(C) The Authors 2017. This is an Open Access article, distributed under the terms of the Creative Commons

Attribution licence (http://creativecommons.org/licenses/by/4.0/), which permits unrestricted re-use,

distribution, and reproduction in any medium, provided the original work is properly cited.

\title{
A n-3 PUFA depletion applied to rainbow trout fry (Oncorhynchus mykiss) does not modulate its subsequent lipid bioconversion capacity
}

\author{
Julie Mellery $^{1 *}$, Jonathan Brel ${ }^{1}$, Junio Dort ${ }^{1}$, Florian Geay $^{2}$, Patrick Kestemont ${ }^{2}$, David S. Francis ${ }^{3}$, \\ Yvan Larondelle ${ }^{1 *}$ and Xavier Rollin ${ }^{1}$ \\ ${ }^{1}$ Institut des Sciences de la Vie, Université catholique de Louvain, Croix du Sud, 2/L7.05.08, 1348 Louvain-la-Neuve, Belgium \\ ${ }^{2}$ Unité de Recherche en Biologie Environnementale et Evolutive, Université de Namur, Rue de Bruxelles, 61, \\ 5000 Namur, Belgium \\ ${ }^{3}$ School of Life and Environmental Sciences, Deakin University, PO Box 423, Warrnambool, VIC 3280, Australia
}

(Submitted 12 August 2016 - Final revision received 11 November 2016 - Accepted 5 December 2016 - First published online 23 January 2017)

\section{Abstract}

Nutritional strategies are currently developed to produce farmed fish rich in $n$-3 long-chain PUFA (LC-PUFA) whilst replacing fish oil by plantderived oils in aquafeeds. The optimisation of such strategies requires a thorough understanding of fish lipid metabolism and its nutritional modulation. The present study evaluated the fatty acid bioconversion capacity of rainbow trout (Oncorbynchus mykiss) fry previously depleted in $n$-3 PUFA through a 60-d pre-experimental feeding period with a sunflower oil-based diet (SO) followed by a 36-d experimental period during which fish were fed either a linseed oil-based diet (LO) (this treatment being called SO/LO) or a fish oil-based diet (FO) (this treatment being called SO/FO). These treatments were compared with fish continuously fed on SO, LO or FO for $96 \mathrm{~d}$. At the end of the 36-d experimental period, SO/LO and SO/FO fish recovered $>80 \%$ of the $n-3$ LC-PUFA reported for LO and FO fish, respectively. Fish fed on LO showed high apparent in vivo elongation and desaturation activities along the $n-3$ biosynthesis pathway. However, at the end of the experimental period, no impact of the fish $n-3$ PUFA depletion was observed on apparent in vivo elongation and desaturation activities of $\mathrm{SO} / \mathrm{LO}$ fish as compared with LO fish. In contrast, the fish $n-3$ PUFA depletion negatively modulated the $n$ - 6 PUFA bioconversion capacity of fish in terms of reduced apparent in vivo elongation and desaturation activities. The effects were similar after 10 or $36 \mathrm{~d}$ of the experimental period, indicating the absence of short-term effects.

Key words: Rainbow trout: Fatty acid metabolism: Lipid bioconversion capacity: Plant-derived oils: Whole body fatty acid balance method

There is an expectation on aquaculture to supply fish rich in health promoting $n-3$ long-chain PUFA ( $n$-3 LC-PUFA), principally EPA $(20: 5 n-3)$ and DHA $(22: 6 n-3)$. It is well established that $n$-3 LC-PUFA impart a host of positive effects on human health $^{(1-3)}$. Moreover, $n-3$ LC-PUFA are essential fatty acids for the optimal growth and health of fish ${ }^{(4,5)}$. Typically, the high $n$-3 LC-PUFA content in farmed fish is derived from the inclusion of marine-derived fish oil as one of the dietary lipid sources within aquafeeds ${ }^{(6,7)}$. However, fish oil has become expensive and difficult to source, and given its status as a finite marine resource, its utilisation is widely criticised from a sustainability perspective ${ }^{(6,7)}$. One of the key sustainable alternatives to fish oil are plant-derived oils ${ }^{(8)}$. In contrast to fish oil, plant-derived oils lack LC-PUFA ${ }^{(8)}$ but are particularly rich in MUFA and C18 PUFA, especially 18:1n-9 and linoleic acid
(LA, 18:2n-6), and in certain sources, such as linseed, camelina or perilla oils, rich in $\alpha$-linolenic acid (ALA, $18: 3 n-3)^{(5,8)}$.

Among fish species, rainbow trout (Oncorbynchus mykiss) and other salmonids possess a relatively high capacity to endogenously convert the dietary essential fatty acids LA and ALA into $n-6$ and $n$-3 LC-PUFA through a combination of desaturation steps requiring $\Delta-6$ and $\Delta-5$ desaturases, elongation steps requiring elongases 2 and 5 and partial $\beta$-oxidation ${ }^{(4,9-13)}$. Previous studies reported increased desaturation and elongation activities without significant detrimental effects to growth and health in salmonids fed on plant-derived oil diets (i.e. sunflower oil ${ }^{(14-16)}$, olive oil ${ }^{(14)}$, palm oil ${ }^{(16)}$, rapeseed $\mathrm{oil}^{(16,17)}$ or linseed oil ${ }^{(14,15,17,18)}$ ), as a blend or sole source. In rainbow trout, the complete dietary replacement of fish oil by linseed oil stimulated fatty acid metabolism along

Abbreviations: ALA, $\alpha$-linolenic acid; CD, coefficient of distance; DGC, daily growth coefficient; FE, feed efficiency; FO, fish oil-based diet; LA, linoleic acid; LC-PUFA, long-chain PUFA; LO, linseed oil-based diet; SO, sunflower oil-based diet; SO/LO, SO until day 60 and then LO from days 61-96; SO/FO, SO until day 60 and then FO from days 61-96.

* Corresponding authors: J. Mellery, email julie.mellery@uclouvain.be; Y. Larondelle, email yvan.larondelle@uclouvain.be 
the bioconversion pathway ${ }^{(18-21)}$. However, while providing a highly suitable source of energy for fish growth and maintenance, it is well documented that the fatty acid composition of the dietary lipid source is reflected in fish tissues. Therefore, despite an increase in the bioconversion capacity, fish fed on plant-based diets invariably contained lower EPA and DHA concentrations as compared with those fed on fish oil-based $\operatorname{diets}^{(15,16,18-21)}$, resulting in major drawbacks from a fish consumption perspective.

There is currently a need to optimise feeding strategies to facilitate the production of farmed fish rich in $n-3$ LC-PUFA whilst minimising fish oil inclusion in aquafeeds. Finishing diets, given before harvest and formulated with fish oil, have been investigated to restore the $n$-3 LC-PUFA content in fish previously fed plant-based diets throughout the grow-out period. Previous studies have demonstrated positive results in many fish species, including Atlantic salmon (Salmo salar) ${ }^{(22,23)}$, common carp (Cyprinus carpio) ${ }^{(24)}$, red hybrid tilapia (Oreochromis sp. $)^{(25)}$, European sea bass (Dicentrarchus labrax $)^{(26)}$, red seabream (Pagrus auratus) $)^{(27)}$ and Murray cod (Maccullochella peelii peelii) $^{(28)}$. An EPA and DHA recovery rate of approximately $80 \%$ was reported at the end of the finishing period in Atlantic salmon previously fed plant-based $\operatorname{diets}^{(22,23)}$. In rainbow trout, finishing diets induced a shift in fish fatty acid profiles to a more fish oil-like composition, but were unable to achieve similar $n$-3 LC-PUFA concentrations as compared with fish fed on fish oil throughout their growth ${ }^{(19,29)}$. The efficiency of a finishing period is determined by a combination of factors including the fish species, the finishing period duration, the fatty acid profile of the alternative oil used ${ }^{(19,25,28)}$ (i.e. the dietary C18 PUFA level ${ }^{(30)}$ ) or the application of a shortterm feed deprivation period before the commencement of the finishing period ${ }^{(29)}$. Although the various feeding strategies that incorporate a finishing strategy demonstrate promising results with undoubtable positive environmental and economic effects, they still rely upon the inclusion of unsustainable dietary fish oil. An alternative strategy involves stimulating fish fatty acid metabolism through nutritional programming during early larval stages as a means of improving the acceptance and conversion of dietary ALA from plant-based diets at juvenile stages ${ }^{(31-33)}$. Vagner et al. ${ }^{(31)}$ observed increased $\Delta-6$ desaturase gene expression in European sea bass juveniles fed an $n$-3 LC-PUFA deficient diet from day 83 post-hatch to day 118, when larvae had been previously fed a low $n$-3 LC-PUFA diet (0.5\% EPA + DHA), as compared with a high $n$-3 LC-PUFA diet $(3.7 \%)$. Moreover, in a study where rainbow trout were fed a plant-based diet containing deuterated ALA, a higher conversion of dietary deuterated ALA to DHA was observed in smaller fish $(0.5-1.5 \mathrm{~g})$ in comparison to larger fish $(6-8 \mathrm{~g})$, highlighting the rapid change of bioconversion capacity with fish size ${ }^{(34)}$. Collectively, the results of these studies provide promising insight into the implementation of feeding strategies for the optimisation of EPA and DHA production and retention in fish tissues. However, for the most part these strategies have not been tested in unison, yielding positive yet incremental benefits. To date, the impacts of combined strategies for increasing $n-3$ LC-PUFA deposition currently remain unknown, ultimately requiring dedicated assessment to determine the extent to which utilisation measures can be optimised.

The aim of the present study was to evaluate the fatty acid bioconversion capacity of rainbow trout fry previously depleted in n-3 PUFA through feeding on a sunflower oil-based diet (SO) during a 60-d pre-experimental period and subsequently fed either a ALA-rich linseed oil-based diet (LO) or an EPA- and DHA-rich fish oil diet (FO) in a 36-d experimental period. Fish growth and bioconversion capacity were evaluated at the end of both periods and on the 10th day of the experimental period, in order to determine the potential impact of a $n-3$ PUFA fish depletion on the apparent in vivo elongation and desaturation activities in fish fed on ALA. Three additional control groups included fish fed on SO ( $n$-3 PUFA deficient diet), LO (ALA-rich diet) or FO (EPA- and DHA-rich diet) throughout the feeding trial.

\section{Methods}

\section{Ethics statement}

The experimental design of the feeding and digestibility trials was approved by the Animal Care and Use Committee of the Université catholique de Louvain (permit number 103203) as per the EU legal frameworks relating to the protection of animals used for scientific purposes (Directive 86/609/CEE) and guidelines of Belgian legislation governing the ethical treatment of animals (Decree M.B. 05.01.1994, 14 November 1993). Both in vivo experiments were conducted at the 'Plateforme technologique et didactique en biologie aquicole Marcel Huet' (Université catholique de Louvain), which is certified for animal services under the permit number LA 1220034. All manipulations were performed under anaesthesia and, if necessary, fish were euthanised using 2-phenoxyethanol at the required concentrations. All efforts were made to minimise fish numbers and suffering. No clinical symptoms were observed within or outside the experimental periods.

\section{Experimental diets}

Experimental diets were formulated to differ in their fatty acid composition and contained either a high amount of $18: 1 n-9$ for SO (blend of sunflower oils rich and low in 18:1n-9, 87:13, $\mathrm{v} / \mathrm{v}$ ), ALA for LO or $n$-3 LC-PUFA for FO. All diets were formulated to cover the fish requirement in LA, while avoiding any excess in that fatty acid, which might compete with ALA regarding desaturations and elongations. In practice, $18: 1 n$-9poor sunflower oil was included to all experimental diets $(5 \mathrm{~g} / \mathrm{kg} \mathrm{DM})$. A higher inclusion of $18: 1 n$-9-poor sunflower oil was used for SO (15 g/ kg DM as compared with $5 \mathrm{~g} / \mathrm{kg} \mathrm{DM})$ in order to obtain a similar LA content in SO and LO. In addition, a sunflower oil rich in 18:1n-9 and poor in LA was added to $\mathrm{SO}$ at a $65 \mathrm{~g} / \mathrm{kg}$ DM concentration to obtain a similar oil inclusion between all experimental diets. The experimental diets were formulated to meet the protein, vitamin and mineral requirements of rainbow trout ${ }^{(5,35)}$ (Table 1 ). The SO, LO and FO had a crude fat content of $94.1,90.4$ and $94.9 \mathrm{mg} / \mathrm{g} \mathrm{DM}$, respectively. This lipid content level was chosen in order to 
Table 1. Components $(\mathrm{g} / \mathrm{kg} \mathrm{DM})$ of the experimental diets formulated with sunflower oil, linseed oil or fish oil

\begin{tabular}{lccc}
\hline & SO & LO & FO \\
\hline Casein $^{*}$ & $288 \cdot 3$ & $288 \cdot 3$ & $288 \cdot 3$ \\
Gelatin $^{*}$ & 50 & 50 & 50 \\
Wheat gluten meal $^{*}$ & 250 & 250 & 250 \\
Modified starch $^{*}$ & $161 \cdot 7$ & $161 \cdot 7$ & $161 \cdot 7$ \\
Glucose* $^{*}$ & 25 & 25 & 25 \\
Agar* $_{\text {Carboxymethylcellulose }}^{*}$ & 10 & 10 & 10 \\
Cellulose $^{*}$ & 40 & 40 & 40 \\
Vitamin premix $^{*} \dagger$ & 20 & 20 & 20 \\
Mineral premix & 10 & 10 & 10 \\
$18: 1 n$-9-rich sunflower oil§ & 65 & 65 & 65 \\
$18: 1 n-9-p o o r$ sunflower oil§ & 65 & 0 & 0 \\
Linseed oilll & 15 & 5 & 5 \\
Cod liver oilף & 0 & 75 & 0 \\
& 0 & 0 & 75
\end{tabular}

SO, sunflower oil-based diet; LO, linseed oil-based diet; FO, fish oil-based diet.

* Sigma-Aldrich.

† Vitamin complex (g/kg premix) according to Rollin et al. ${ }^{(35)}$ : retinol acetate 0.67 , ascorbic acid 120, cholecalciferol $0 \cdot 1$, a-tocopherol acetate $34 \cdot 2$, menadione $2 \cdot 2$, thiamin $5 \cdot 6$, riboflavin 12 , pyridoxine 4.5 , calcium pantothenate $14 \cdot 1, p$-aminobenzoic acid 40 , cyanocobalamin 0.03 , niacin 30 , biotin 0.1 , choline chloride 350 , folic acid 1.5 , inositol 50 , canthaxanthin 10 , butylated hydroxytoluene 1.5 , butylated hydroxyanisole 1.5 , a-cellulose $322 \cdot 1$.

‡ Mineral complex (g/kg premix) according to Rollin et al. ${ }^{(35)}: \mathrm{CaHPO}_{4} \cdot 2 \mathrm{H}_{2} \mathrm{O} 295 \cdot 5$, $\mathrm{Ca}\left(\mathrm{H}_{2} \mathrm{PO}_{4}\right)_{2} . \mathrm{H}_{2} \mathrm{O} 217, \mathrm{NaHCO}_{3} 94.5, \mathrm{Na}_{2} \mathrm{SeO}_{3} .5 \mathrm{H}_{2} \mathrm{O} 0.011, \mathrm{KCl} 100, \mathrm{NaCl} 172 \cdot 4$ $\mathrm{KI} 0.2, \mathrm{MgCl}_{2} 63.7, \mathrm{MgSO}_{4} .7 \mathrm{H}_{2} \mathrm{O} 70.32, \mathrm{MnSO}_{4} . \mathrm{H}_{2} \mathrm{O} 1.52, \mathrm{FeSO}_{4} .7 \mathrm{H}_{2} \mathrm{O} 12.41$, $\mathrm{CuSO}_{4} .5 \mathrm{H}_{2} \mathrm{O} 0.4, \mathrm{ZnSO}_{4} .7 \mathrm{H}_{2} \mathrm{O} 10$.

$\$$ Vandemoortele.

II Lambert Chemicals.

ๆ Certa.

obtain a quick and efficient depletion in $n-3$ PUFA in the fish submitted to the SO treatment. Moreover, diets were formulated to obtain a targeted crude protein content of $520 \mathrm{mg} / \mathrm{g}$ DM and a targeted energy content of $20 \mathrm{MJ} / \mathrm{kg} \mathrm{DM}$. SO was deficient in n-3 PUFA ( $1.2 \%$ of identified fatty acids), whereas LO was particularly rich in ALA (39.3\% of identified fatty acids, $99.8 \%$ of $n-3$ PUFA), and FO rich in EPA and DHA (7.6 and $9 \%$ of identified fatty acids, 33.7 and $40 \%$ of $n$-3 PUFA, respectively) (Table 2). Chromic oxide was added at $10 \mathrm{~g} / \mathrm{kg}$ DM to each experimental diets intended for the digestibility trial in order to serve as indigestible marker. The dry dietary components were mixed, homogenised using an electronic mixer (Kenwood Ltd), and extruded (HI 2251; Simplex). The diets were subsequently freeze-dried, manually crushed and then sieved to obtain pellets from 0.8 to $1.6 \mathrm{~mm}$. The dry pellets were finally coated with oils and the diets were shaken several times for $48 \mathrm{~h}$ at $4^{\circ} \mathrm{C}$ before storage at $-20^{\circ} \mathrm{C}$ until feeding or analysis.

\section{Fish husbandry}

Fertilised eggs from domesticated rainbow trout breeders were supplied by a commercial fish farm (La Fontaine aux Truites). After hatching, rainbow trout fry were fed a commercial diet for 2 months before the feeding trial. After $48 \mathrm{~h}$ of feed deprivation, rainbow trout fry (mean initial body weight $0 \cdot 70$ (SEM 0.01) g/fish) were randomly distributed among seventeen tanks (11-litre capacity) to obtain 225 fish/tank. Fish of two tanks were sampled as an initial sample, weighed and stored at $-20^{\circ} \mathrm{C}$ for subsequent analyses. Throughout the feeding trial, feeding was carried out by hand twice daily (08.30 and 16.00 hours) to apparent satiation
Table 2. Fatty acid composition (mg/g DM) of the experimental diets

\begin{tabular}{|c|c|c|c|}
\hline Fatty acids & SO & LO & $\mathrm{FO}$ \\
\hline $14: 0$ & 0.1 & 0.1 & 2.7 \\
\hline $16: 0$ & 4.9 & $5 \cdot 7$ & $9 \cdot 0$ \\
\hline $18: 0$ & $2 \cdot 0$ & $2 \cdot 4$ & 1.4 \\
\hline $16: 1 n-7$ & 0.1 & 0.1 & 3.4 \\
\hline $18: 1 n-7$ & 1.0 & 0.7 & 1.9 \\
\hline $18: 1 n-9$ & 48.4 & $13 \cdot 2$ & 11.6 \\
\hline $20: 1 n-9$ & 0.2 & 0.1 & 4.4 \\
\hline $18: 2 n-6$ & 15.9 & $17 \cdot 6$ & 9.7 \\
\hline $18: 3 n-6$ & I & 0.1 & 0.04 \\
\hline $20: 2 n-6$ & I & 0.02 & 0.2 \\
\hline $20: 3 n-6$ & I & 0.02 & 0.05 \\
\hline $20: 4 n-6$ & l & / & 0.2 \\
\hline $22: 4 n-6$ & I & I & / \\
\hline $22: 5 n-6$ & I & l & 0.1 \\
\hline $18: 3 n-3$ & 0.9 & $26 \cdot 3$ & $1 \cdot 2$ \\
\hline $18: 4 n-3$ & I & / & 0.9 \\
\hline $20: 3 n-3$ & l & 0.1 & 0.1 \\
\hline $20: 4 n-3$ & / & / & 0.5 \\
\hline $20: 5 n-3$ & / & l & 4.5 \\
\hline $22: 5 n-3$ & / & l & 0.8 \\
\hline $22: 6 n-3$ & / & / & $5 \cdot 3$ \\
\hline Total & 74.4 & 66.9 & $59 \cdot 1$ \\
\hline$\Sigma S F A^{*}$ & $7 \cdot 7$ & 8.5 & 13.5 \\
\hline ¿MUFA† & 49.9 & $14 \cdot 3$ & 21.9 \\
\hline$\Sigma$ C18 n-6 PUFA & $15 \cdot 9$ & $17 \cdot 8$ & 9.7 \\
\hline$\Sigma n-6$ LC-PUFA§ & 0 & 0.04 & 0.6 \\
\hline$\Sigma$ C18 n-3 PUFAll & 0.9 & $26 \cdot 3$ & $2 \cdot 1$ \\
\hline$\Sigma n-3$ LC-PUFAף & 0 & $0 \cdot 1$ & $11 \cdot 2$ \\
\hline$n-3: n-6^{\star \star}$ & 0.1 & 1.5 & $1 \cdot 3$ \\
\hline n-3:n-6 LC-PUFA†† & 0 & $1 \cdot 2$ & $18 \cdot 9$ \\
\hline
\end{tabular}

SO, sunflower oil-based diet; LO, linseed oil-based diet; FO, fish oil-based diet; LC-PUFA, long-chain PUFA.

* Sum of SFA, includes 20:0,22:0 and 24:0.

† Sum of MUFA, includes $14: 1 n-5,22: 1 n-9$ and $24: 1 n-9$

$\ddagger$ Sum of $n-6$ PUFA with $18 \mathrm{C}$.

$\S$ Sum of $n-6$ LC-PUFA with $20 \mathrm{C}$ and 22C.

II Sum of $n-3$ PUFA with $18 \mathrm{C}$.

Tा Sum of $n$-3 LC-PUFA with $20 \mathrm{C}$ and 22C.

** Ratio of total $n$-3 PUFA:total $n$-6 PUFA.

†† Ratio of $n$-3 LC-PUFA: $n-6$ LC-PUFA.

(pellets from 0.8 to $1.6 \mathrm{~mm}$, depending on the fish size). Fish were subjected to a $12 \mathrm{~h}$ light- $12 \mathrm{~h}$ dark cycle photoperiod at a mean water temperature of $14^{\circ} \mathrm{C}$ with a 1 litre/min flow. From the 1 st to the 60th feeding day, fish of nine tanks were fed on SO ( $n 9)$, three tanks were fed on LO ( $n$ 3) and three tanks were fed on FO ( $n$ 3). On the 20th day, fish were transferred to larger tanks (50 litre capacity) supplied by water at $11.5 \pm 0.5^{\circ} \mathrm{C}$ on a 5 litres/min flow basis. At the end of the 60-d pre-experimental period, considered to be long enough to highly reduce the $n-3$ PUFA content of fish fed on SO, six tanks previously held on SO were switched, either to LO (three tanks), or FO (three tanks). The second feeding period lasted $36 \mathrm{~d}$. The experimental conditions were therefore named as SO, LO and FO for fish fed on SO, $\mathrm{LO}$ and FO ( $n$ 3), respectively, during $96 \mathrm{~d}$, and as SO/LO and SO/ FO ( $n$ 3) for fish fed on SO during the first $60-\mathrm{d}$ pre-experimental period and then on $\mathrm{LO}$ or FO, respectively, during the second 36-d experimental period. Throughout the feeding trial, the biomass was determined every 10th feeding day after $48 \mathrm{~h}$ of feed deprivation. On days 60, 70 and 96, fish were weighed after $48 \mathrm{~h}$ of feed deprivation and fifteen fish of each tank were then euthanised with 2-phenoxyethanol, freeze-dried, homogenised and kept frozen $\left(-20^{\circ} \mathrm{C}\right)$ until chemical analysis. At the end of the 
experimental period, the remaining fish from each tank fed their specific diet until the digestibility trial. The digestibility trial was performed with 5 (SEM 0.05) kg of fish in circular tanks (130 litre capacity). Fish remained under experiment until accumulating sufficient faeces. The water was supplied at a 4 litres/min flow, the temperature was maintained at $11 \pm 1^{\circ} \mathrm{C}$ throughout the trial and fish were subjected to a $12 \mathrm{~h}$ light $-12 \mathrm{~h}$ dark cycle photoperiod. Fish were fed manually twice daily (09.00 and 17.00 hours) to apparent satiation whilst avoiding any undesirable mixing of feed and faeces. Faeces were collected continuously through a rotating automatic faeces collector system ${ }^{(36)}$. Faeces collected per tank were weighed, freeze-dried, homogenised and stored at $-20^{\circ} \mathrm{C}$ until further analyses.

\section{Chemical analysis}

The DM and crude fat contents were analysed following analytical methods from the Association of Official Analytical Chemists $^{(37)}$. In brief, DM was measured by drying samples at $105^{\circ} \mathrm{C}$ for $16 \mathrm{~h}$ and the crude fat content was evaluated using diethyl ether extraction according to Soxhlet method. The chromic oxide concentration in diets and faeces was determined following a protocol involving acid digestion followed by oxidation before photometric measurement (Cecil Instruments) at $350 \mathrm{~nm}^{(38)}$. The fatty acid composition of diets, fish and faeces was evaluated after lipid extraction of samples following the Folch method ${ }^{(39)}$ with subsequent modifications $^{(40)}$. In brief, lipids from $1 \mathrm{~g}$ of dried sample were extracted by $60 \mathrm{ml}$ of chloroform-methanol (2:1, v/v) (VWR Chemicals). Tridecanoic acid (Sigma-Aldrich) was used as internal standard for fatty acid quantification. The extracted fatty acids were converted into fatty acid methyl esters via methylation under alkaline conditions $(\mathrm{KOH}$ in methanol, $0.1 \mathrm{~m}$, at $70^{\circ} \mathrm{C}$ for $60 \mathrm{~min}$ ) and then under acidic conditions ( $\mathrm{HCl}$ in methanol, $1.2 \mathrm{M}$, at $70^{\circ} \mathrm{C}$ for $20 \mathrm{~min}$ ). The resultant fatty acid methyl esters were subsequently separated by GC. The GC Trace (Thermo Scientific) was equipped with an RT2560 capillary column $(100 \mathrm{~m} \times 0.25 \mathrm{~mm}$ internal diameter, $0.2 \mu \mathrm{m}$ film thickness; Restek), an 'on column' automatic injector and a flame ionisation detector kept at a constant temperature of $255^{\circ} \mathrm{C}$. The system used $\mathrm{H}$ as the carrier gas at an operating pressure of $200 \mathrm{kPa}$. The oven temperature programme was as follows: an initial temperature of $80^{\circ} \mathrm{C}$, which progressively increased at $25^{\circ} \mathrm{C} / \mathrm{min}$ up to $175^{\circ} \mathrm{C}$, a holding temperature of $175^{\circ} \mathrm{C}$ during $25 \mathrm{~min}$ followed by an increase at $10^{\circ} \mathrm{C} / \mathrm{min}$ up to $205^{\circ} \mathrm{C}$, a holding temperature of $205^{\circ} \mathrm{C}$ during $4 \mathrm{~min}$ followed by an increase at $10^{\circ} \mathrm{C} / \mathrm{min}$ up to $225^{\circ} \mathrm{C}$ and a holding temperature of $225^{\circ} \mathrm{C}$ during $20 \mathrm{~min}$. Each peak was identified by comparison of retention times with those for pure methyl ester standards (Larodan and Nu-Check Prep). Data processing was operated via ChromQuest software 3.0 (Thermo Finnigan). The final results are expressed in $\mathrm{mg} / \mathrm{g}$ DM.

\section{Performance parameters and fatty acid metabolism computation}

Daily growth coefficient (DGC) was calculated as follows: DGC $\left(\mathrm{g}^{1 / 3} / \mathrm{d} \times 1000\right)=1000 \times\left((\text { final fish weight }(\mathrm{g}))^{1 / 3}-(\right.$ initial fish weight $(\mathrm{g}))^{1 / 3}$ )/feeding d. Daily feed intake was calculated as the percentage of biomass. Feed efficiency (FE, g/g DM) was calculated as the ratio between fish weight gain $(\mathrm{g})$ and dry feed intake (g DM). The apparent fatty acid digestibility was assessed using the standard formula: $100-\left(100 \times\left(\mathrm{Cr}_{2} \mathrm{O}_{3}\right.\right.$ in diet $(\mathrm{mg} / \mathrm{g} \mathrm{DM})) /\left(\mathrm{Cr}_{2} \mathrm{O}_{3}\right.$ in faeces $\left.(\mathrm{mg} / \mathrm{g} \mathrm{DM})\right) \times($ fatty acid in faeces $(\mathrm{mg} / \mathrm{g} \mathrm{DM})) /($ fatty acid in diet $(\mathrm{mg} / \mathrm{g} \mathrm{DM})))$. The coefficient of distance (CD) was implemented to compare fatty acid concentrations between two treatments and was calculated as previously described ${ }^{(41)}$. The estimation of the apparent in vivo fatty acid metabolism was calculated via the implementation of the whole body fatty acid balance method, as initially proposed and described by Turchini et $a .^{(42)}$ and later modified ${ }^{(20,43)}$.

\section{Statistical analysis}

All data are presented as mean values with their standard errors ( $n$ 2, 3 or 9, as stated). Before statistical analysis, data were subjected to $\log$ or square root transformation if identified as non-homogenous (Levene's test) to meet the assumptions for statistical methods. The significance of difference between dietary treatments was determined using one-way ANOVA at a significance level of $\alpha 5 \%$, followed by Tukey's (parametric with $\alpha 5 \%$ ) or Wilcoxon's (non-parametric with $\alpha 1.69 \%$ ) post hoc tests. Statistical analysis was carried out using $\mathrm{JMP}^{\circledR}$ Pro 12 (SAS).

\section{Results}

\section{Fish growth performance}

The experimental diets were readily accepted by fish and mortality throughout the feeding trial was low and unrelated to the dietary treatment (mean mortality rate $<0.01 \% / d$ ). In contrast, fish weight and growth performance were highly impacted by the dietary lipid source. Fish fed on SO throughout the feeding trial recorded the lowest final weight (22.9 (SEM 0.9) $\mathrm{g} /$ fish) whereas fish fed on LO and FO recorded the highest final weights (48.4 (SEM 1.2) and 51.5 (SEM 0.9) g/fish, respectively) (Fig. 1). This trend manifested further in decreased DGC and FE in fish subjected to the SO treatment over the course of the feeding trial (Table 3). In LO fish, a reduced DGC was noticed in comparison to fish fed on FO at the end of the 60-d pre-experimental period, but not at the end of the feeding trial. The replacement of SO by LO or FO for $36 \mathrm{~d}$ also induced significant differences. The SO/LO and SO/FO final fish weights were higher than those of fish fed on SO for $96 \mathrm{~d}$, but did not reach those of fish constantly fed on LO and FO for $96 \mathrm{~d}$ (Fig. 1). DGC values were also higher for the SO/LO and SO/FO treatments as compared with the SO treatment, and similar to those observed for the LO and FO fish groups (Table 3). Moreover, an increased FE was recorded for SO/LO and SO/FO fish as compared with SO fish. These increased FE were similar to those of fish fed on LO and FO for $96 \mathrm{~d}$. The SO/LO fish had a significantly reduced DGC as compared with the SO/FO fish group but similar final fish weights, feed intake and FE. 


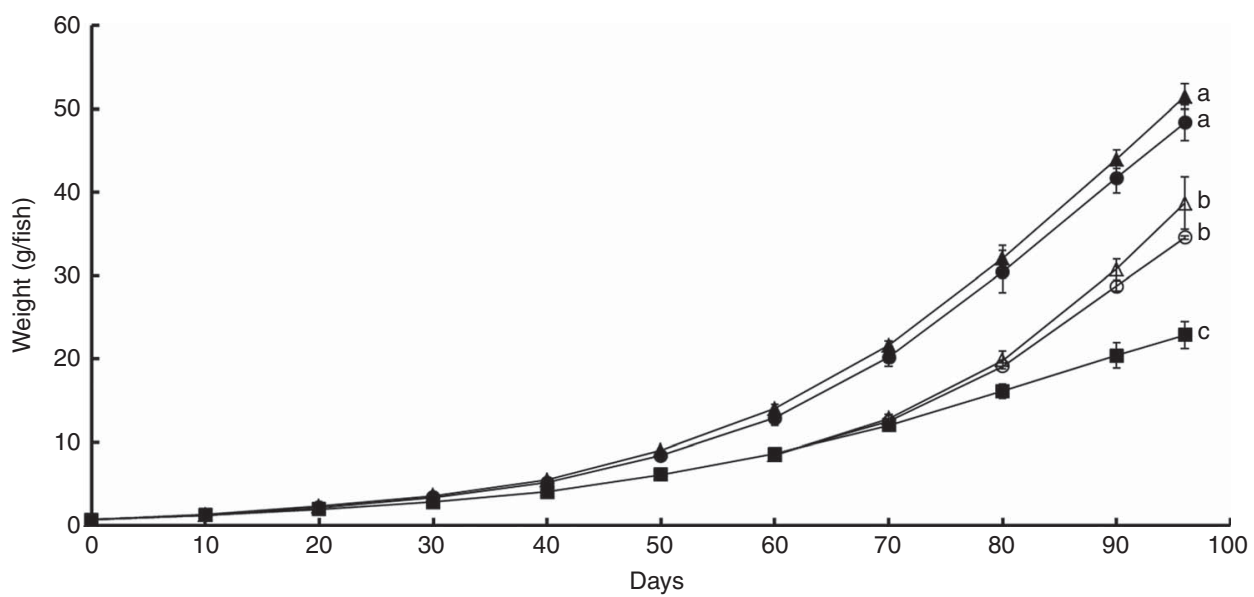

Fig. 1. Mean weight (g/fish) of rainbow trout at each sampling time point over the 60-d pre-experimental period and the 36-d experimental period. Values are means ( $n 3$ except sunflower oil-based diet (SO) treatment from starting day until day 60 for which $n 9$ ), with their standard errors. The fish weight was impacted by the dietary treatment regarding the lowest weight of fish fed SO ( $\mathbf{\square})$ and the highest weights of fish fed on linseed oil-based diet (LO, $\bullet$ ) or fish oil-based diet (FO, $\mathbf{A}$ ) during $96 \mathrm{~d}$. Intermediate fish weights were reported when feeding fish on SO for $60 \mathrm{~d}$ and then on LO (SO/LO, o) or FO (SO/FO, $\Delta$ ) for $36 \mathrm{~d}$. ${ }^{\text {a,b,c }}$ Mean values with unlike superscript letters were significantly different (Tukey's post hoc test, $a 5 \%$ ).

Table 3. Growth performance of rainbow trout fed on diets differing in fatty acid composition during a 60-d pre-experimental feeding period (days 1-60) followed by a 36-d experimental period (days 61-96)

(Mean values with their standard errors; $n 3$ except for sunflower oil-based diet (SO) for days 1 to 60 period $(n$ 9))

\begin{tabular}{|c|c|c|c|c|c|c|c|c|c|c|}
\hline & \multicolumn{2}{|c|}{ So } & \multicolumn{2}{|c|}{ LO } & \multicolumn{2}{|c|}{$\mathrm{FO}$} & \multicolumn{2}{|c|}{ SO/LO } & \multicolumn{2}{|c|}{ SO/FO } \\
\hline & Mean & SEM & Mean & SEM & Mean & SEM & Mean & SEM & Mean & SEM \\
\hline \multicolumn{11}{|l|}{ Days $1-60$} \\
\hline DGC $\left(g^{1 / 3} / d \times 1000\right)$ & $19 \cdot 3^{\mathrm{c}}$ & 0.1 & $24 \cdot 2^{b}$ & 0.5 & $25 \cdot 4^{a}$ & 0.3 & l & I & 1 & 1 \\
\hline Feed intake $(\% / d)$ & $2.9^{b}$ & 0.0 & $3 \cdot 2^{\mathrm{a}}$ & 0.1 & $3.1^{\mathrm{a}}$ & 0.0 & 1 & 1 & 1 & 1 \\
\hline FE & $1.4^{b}$ & 0.0 & $1 \cdot 5^{\mathrm{a}, \mathrm{b}}$ & 0.1 & $1.6^{\mathrm{a}}$ & 0.0 & 1 & 1 & I & 1 \\
\hline \multicolumn{11}{|l|}{ Days $1-96$} \\
\hline DGC $\left(\mathrm{g}^{1 / 3} / \mathrm{d} \times 1000\right)$ & $20 \cdot 3^{b}$ & 0.4 & $28.7^{\mathrm{a}}$ & 0.3 & $29 \cdot 5^{a}$ & 0.2 & 1 & 1 & 1 & 1 \\
\hline Feed intake $(\% / d)$ & $2 \cdot 8^{\mathrm{b}}$ & 0.0 & $3.0^{\mathrm{a}}$ & 0.1 & $2 \cdot 9^{a, b}$ & 0.0 & l & l & l & I \\
\hline FE & $1 \cdot 1^{b}$ & 0.0 & $1 \cdot 3^{\mathrm{a}}$ & 0.0 & $1.4^{\mathrm{a}}$ & 0.0 & 1 & 1 & 1 & 1 \\
\hline \multicolumn{11}{|l|}{ Days $61-96$} \\
\hline$D G C\left(g^{1 / 3} / d \times 1000\right)$ & $21.9^{c}$ & 0.7 & $36 \cdot 1^{a, b}$ & 0.0 & $36 \cdot 4^{a, b}$ & 0.9 & $33 \cdot 7^{b}$ & 0.1 & $37 \cdot 3^{a}$ & 1.2 \\
\hline Feed intake $(\% / \mathrm{d})$ & $2 \cdot 5^{\mathrm{c}}$ & 0.0 & $2 \cdot 7^{\mathrm{b}, \mathrm{c}}$ & 0.0 & $2 \cdot 5^{\mathrm{c}}$ & 0.1 & $2 \cdot 8^{a, b}$ & 0.0 & $2.9^{\mathrm{a}}$ & 0.0 \\
\hline FE & $1.0^{\mathrm{b}}$ & 0.0 & $1.3^{\mathrm{a}}$ & 0.0 & $1.4^{\mathrm{a}}$ & 0.0 & $1 \cdot 3^{\mathrm{a}}$ & 0.0 & $1.4^{\mathrm{a}}$ & 0.0 \\
\hline
\end{tabular}

LO, linseed oil-based diet; FO, fish oil-based diet; SO/LO, SO until day 60 and then LO from days 61-96; SO/FO, SO until day 60 and then FO from days $61-96$; DGC, daily growth coefficient; FE, feed efficiency.

a,b,c Mean values within a row with unlike superscript letters were significantly different (Tukey's (parametric, a $5 \%$ ) or Wilcoxon's (non-parametric, a 1.69\%) post hoc tests).

\section{Fish fatty acid composition}

Throughout the feeding trial, fish fed on LO recorded the highest C18 n-6 PUFA concentration while fish fed on SO recorded the highest $n$-6 LC-PUFA concentration (Tables 4 and 5), despite the absence of $n-6$ LC-PUFA in SO (Table 2). The pre-experimental period induced a high depletion in $n$-3 PUFA for fish fed on SO as these recorded the lowest concentrations of C18 n-3 PUFA and $n$-3 LC-PUFA (0.79 (SEM 0.10) and 2.75 (SEM 0.47) mg/g DM throughout the feeding trial, respectively). In contrast, the highest C18 n-3 PUFA and n-3 LC-PUFA concentrations were, respectively, reported in fish fed on LO (42.68 (sEm 0.74) mg/g DM) and in fish fed on FO (25.82 (SEM 0.94) mg/g DM) (Tables 4 and 5). Concentrations of $18: 4 n-3,20: 3 n-3$ and $20: 4 n-3$ were significantly higher in fish fed on LO, while fish fed on FO recorded the highest EPA and DHA concentrations. On the 10th day of the experimental period (day 70), the SO/LO fish recovered $57 \%(\mathrm{CD} 3.9)$ of the $n$-3 LC-PUFA found in fish fed on LO for $70 \mathrm{~d}$. Similarly, the SO/FO fish recovered $51 \%$ (CD 9) of the $n$-3 LC-PUFA found in fish fed on FO for $70 \mathrm{~d}$ (Table 5). At the end of the experimental period, the $n-3$ LC-PUFA of SO/LO and $\mathrm{SO} / \mathrm{FO}$ fish almost reached those of fish fed on LO and FO with a recovery rate of $82 \%$ (CD 1.8) and $84 \%$ (CD 2.9), respectively. In terms of DHA, the SO/LO fish recovered $62 \%$ (CD 3.4) and 84\% (CD 1.6) of the DHA found in fish fed on LO on the 10th day and at the end of the 36- $\mathrm{d}$ experimental period, respectively. The SO/FO fish recovered 49\% (CD 8.6) and $85 \%$ (CD 2.8) of the DHA found in fish fed on FO, on the 10th day and at the end of the experimental period, respectively.

\section{In vivo fatty acid metabolism}

Over the course of the entire feeding trial, total apparent in vivo SFA and MUFA elongation and $\Delta-9$ desaturation activities were 
Table 4. Fatty acid composition ( $\mathrm{mg} / \mathrm{g} \mathrm{DM}$ ) of fish held on dietary treatments differing in the dietary lipid source on the starting and at the end of the 60-d pre-experimental feeding period

(Mean values with their standard errors; $n 3$ except initial treatment $(n 2)$ )

\begin{tabular}{|c|c|c|c|c|c|c|c|c|}
\hline \multirow[b]{3}{*}{ Fatty acids } & & & \multicolumn{6}{|c|}{ Day 60} \\
\hline & \multicolumn{2}{|c|}{ Initial } & \multicolumn{2}{|c|}{ so } & \multicolumn{2}{|c|}{ LO } & \multicolumn{2}{|c|}{ FO } \\
\hline & Mean & SEM & Mean & SEM & Mean & SEM & Mean & SEM \\
\hline $14: 0$ & 7.65 & 0.18 & $2 \cdot 83^{b}$ & 0.01 & $2 \cdot 30^{\mathrm{c}}$ & 0.09 & $7 \cdot 08^{a}$ & 0.16 \\
\hline $16: 0$ & $26 \cdot 75$ & 0.67 & $30 \cdot 79^{c}$ & 0.08 & $33.12^{b}$ & 0.36 & $39.01^{a}$ & 1.21 \\
\hline $18: 0$ & 4.74 & 0.39 & $8 \cdot 31^{\mathrm{b}}$ & 0.07 & $10 \cdot 26^{a}$ & 0.26 & $8.05^{\mathrm{b}}$ & 0.36 \\
\hline $16: 1 n-7$ & 8.09 & 0.17 & $10 \cdot 00^{b}$ & 0.09 & $9 \cdot 72^{\mathrm{b}}$ & 0.27 & $15 \cdot 90^{\mathrm{a}}$ & 0.56 \\
\hline $18: 1 n-7$ & 4.08 & 0.04 & $4 \cdot 28^{\mathrm{b}}$ & $0 \cdot 10$ & $3.79^{b}$ & $0 \cdot 10$ & $6 \cdot 82^{\mathrm{a}}$ & 0.22 \\
\hline $18: 1 n-9$ & 17.51 & 0.53 & $124 \cdot 74^{a}$ & 0.89 & $59.00^{\mathrm{b}}$ & 0.92 & $49 \cdot 44^{c}$ & 1.20 \\
\hline $20: 1 n-9$ & 8.70 & 0.18 & $4 \cdot 36^{b}$ & 0.07 & $2 \cdot 00^{c}$ & 0.02 & $9 \cdot 78^{a}$ & 0.37 \\
\hline $18: 2 n-6$ & 5.08 & 0.26 & $25 \cdot 37^{\mathrm{b}}$ & 0.33 & $36 \cdot 33^{a}$ & 0.81 & $22 \cdot 91^{\mathrm{b}}$ & 0.74 \\
\hline $18: 3 n-6$ & 0.13 & 0.00 & $2 \cdot 77^{a}$ & 0.05 & $1.23^{b}$ & 0.09 & $0.43^{c}$ & 0.01 \\
\hline $20: 2 n-6$ & 0.48 & 0.00 & $1.25^{\mathrm{b}}$ & 0.03 & $1.58^{\mathrm{a}}$ & 0.05 & $1.54^{\mathrm{a}}$ & 0.07 \\
\hline $20: 3 n-6$ & 0.25 & 0.01 & $2 \cdot 32^{\mathrm{a}}$ & 0.02 & $1.69^{\mathrm{b}}$ & 0.07 & $1.04^{c}$ & 0.01 \\
\hline $20: 4 n-6$ & 1.30 & 0.02 & $3 \cdot 38^{a}$ & 0.02 & $0.97^{\mathrm{b}}$ & 0.03 & $1.03^{b}$ & 0.01 \\
\hline $22: 4 n-6$ & 0.05 & 0.01 & $0.41^{\mathrm{a}}$ & 0.02 & $0.06^{\mathrm{b}}$ & 0.00 & $0.08^{\mathrm{b}}$ & 0.01 \\
\hline $22: 5 n-6$ & 0.29 & 0.05 & $3 \cdot 24^{a}$ & 0.07 & $0.20^{c}$ & 0.01 & $0.32^{\mathrm{b}}$ & 0.01 \\
\hline $18: 3 n-3$ & 2.47 & 0.20 & $0.64^{\mathrm{c}}$ & 0.05 & $36 \cdot 27^{a}$ & 0.74 & $2 \cdot 15^{\mathrm{b}}$ & 0.06 \\
\hline $18: 4 n-3$ & $2 \cdot 72$ & 0.13 & $0.35^{c}$ & 0.01 & $4.94^{\mathrm{a}}$ & 0.33 & $1 \cdot 23^{\mathrm{b}}$ & 0.02 \\
\hline $20: 3 n-3$ & 0.62 & 0.04 & $0.00^{C}$ & 0.00 & $1.66^{\mathrm{a}}$ & 0.10 & $0.40^{\mathrm{b}}$ & 0.03 \\
\hline $20: 4 n-3$ & 1.53 & 0.07 & $0.06^{\mathrm{c}}$ & 0.00 & $2 \cdot 11^{\mathrm{a}}$ & 0.09 & $1.00^{\mathrm{b}}$ & 0.06 \\
\hline $20: 5 n-3$ & $10 \cdot 62$ & 0.25 & $0.58^{c}$ & 0.02 & $2 \cdot 31^{\mathrm{b}}$ & 0.09 & $4 \cdot 61^{a}$ & 0.11 \\
\hline $22: 5 n-3$ & 2.55 & 0.05 & $0.15^{\mathrm{c}}$ & 0.01 & $0.79^{\mathrm{b}}$ & 0.02 & $1.49^{\mathrm{a}}$ & 0.05 \\
\hline $22: 6 n-3$ & 30.57 & 0.76 & $2 \cdot 67^{\mathrm{C}}$ & 0.00 & $10 \cdot 33^{b}$ & 0.23 & $17 \cdot 77^{\mathrm{a}}$ & 0.62 \\
\hline Total & 139.94 & 4.05 & $230 \cdot 97^{a}$ & 1.44 & $222 \cdot 07^{a}$ & 3.55 & $195 \cdot 42^{\mathrm{b}}$ & 5.82 \\
\hline$\Sigma \mathrm{SFA}^{*}$ & 39.54 & 1.24 & 43.37 & $0 \cdot 10$ & $46 \cdot 32$ & 0.21 & 54.67 & 1.75 \\
\hline$\Sigma$ MUFA† & 41.74 & 0.96 & $144 \cdot 40^{\mathrm{a}}$ & 1.05 & $75 \cdot 28^{\mathrm{C}}$ & 1.22 & $84.76^{b}$ & 2.44 \\
\hline$\Sigma$ C18 $n-6$ PUFA $\ddagger$ & $5 \cdot 21$ & 0.26 & $28 \cdot 14^{\mathrm{b}}$ & 0.29 & $37.56^{\mathrm{a}}$ & 0.88 & $23 \cdot 33^{c}$ & 0.74 \\
\hline$\Sigma n-6$ LC-PUFA§ & $2 \cdot 36$ & 0.09 & $10 \cdot 60^{\mathrm{a}}$ & 0.10 & $4.50^{\mathrm{b}}$ & 0.09 & $4.00^{\mathrm{C}}$ & 0.10 \\
\hline$\Sigma$ C18 $n-3$ PUFAll & 5.19 & 0.34 & $0.99^{C}$ & 0.05 & $41 \cdot 21^{\mathrm{a}}$ & 0.92 & $3 \cdot 38^{b}$ & 0.08 \\
\hline$\Sigma n-3$ LC-PUFA & 45.89 & 1.17 & $3.47^{c}$ & 0.03 & $17 \cdot 21^{b}$ & 0.47 & $25 \cdot 27^{a}$ & 0.79 \\
\hline$n-3: n-6^{\star *}$ & $6 \cdot 75$ & 0.11 & $0.12^{\mathrm{C}}$ & 0.00 & $1.39^{a}$ & 0.00 & $1.05^{\mathrm{b}}$ & 0.00 \\
\hline$n-3: n-6$ LC-PUFA†† & 19.44 & 0.22 & $0.33^{c}$ & 0.00 & $3.83^{b}$ & 0.04 & $6 \cdot 31^{\mathrm{a}}$ & 0.04 \\
\hline
\end{tabular}

SO, sunflower oil-based diet; LO, linseed oil-based diet; FO, fish oil-based diet; LC-PUFA, long-chain PUFA ( $\geq 20 \mathrm{C})$.

a,b,c Mean values within a row with unlike superscript letters were significantly different (Tukey's (parametric, a $5 \%$ ) or Wilcoxon's (non-parametric, a $1.69 \%$ ) post hoc tests on square root transformed final condition values).

* Sum of SFA, includes 20:0, 22:0 and 24:0.

† Sum of MUFA, includes $14: 1 n-5,22: 1 n-9$ and $24: 1 n-9$.

$\ddagger$ Sum of $n-6$ PUFA with $18 \mathrm{C}$.

$\S$ Sum of $n-6$ LC-PUFA with $20 \mathrm{C}$ and $22 \mathrm{C}$

II Sum of $n$-3 PUFA with 18C.

II Sum of $n-3$ LC-PUFA with $20 \mathrm{C}$ and $22 \mathrm{C}$.

${ }_{\star \star}$ Ratio of total $n$-3 PUFA:total $n-6$ PUFA.

†† Ratio of $n$-3 LC-PUFA: $n-6$ LC-PUFA.

highest in fish subjected to the LO and FO treatments, while fish receiving $\mathrm{SO}$ recorded the highest total apparent in vivo SFA and MUFA $\beta$-oxidation (Tables 6 and 7 ). Within the $n$ - 6 PUFA family, fish fed on SO demonstrated a higher apparent in vivo elongation as well as higher $\Delta-5$ and $\Delta-6$ desaturation activities in comparison to those fed on LO and FO (Tables 6 and 7). In contrast, within the $n-3$ PUFA family, the highest apparent in vivo elongation, $\Delta-5$ and $\Delta-6$ desaturation activities were displayed in fish subjected to the LO treatment (Table 6). The apparent in vivo activities of fish at the end and on the 10th day of the experimental period are reported in Tables 7 and 8, respectively. At the end of the experimental period, fish of the SO/LO group recorded lower apparent in vivo enzyme activities as compared with fish fed on LO at each elongation and desaturation step of the $n-6$ pathway. Similar observations were reported on the 10th day of the experimental period, but only significantly for the apparent in vivo elongation activity (Table 8).
In contrast, no differences in apparent in vivo elongation and desaturation activities within the $n-3$ pathway were observed between SO/LO and LO treatments, at the end of the trial or on the 10th day of the experimental period (Tables 7 and 8). Considering both $n-6$ and $n-3$ pathways, similar apparent in vivo $\Delta-5$ and $\Delta-6$ desaturation activities were reported between SO/LO and LO fish groups. With respect to the dietary replacement of SO by $\mathrm{FO}(\mathrm{SO} / \mathrm{FO})$, no statistical differences in apparent in vivo $n-6$ and $n-3$ PUFA enzyme activities were seen between SO/FO and FO fish groups on the 10th day and at the end of the experimental period (Tables 7 and 8).

\section{Discussion}

The aim of the present study was to evaluate the fatty acid bioconversion capacity of rainbow trout fry previously depleted in $n$-3 PUFA over a $60-\mathrm{d}$ pre-experimental period and 
Table 5. Fatty acid composition (mg/g DM) of fish held on dietary treatments differing in dietary lipid source on the 10th (day 70) and the end (day 96) of the 36-d experimental period (Mean values with their standard errors; $n 3$ except sunflower oil-based diet (SO) until day 60 and then fish oil-based diet (FO) from days $61-96$ (SO/FO) treatment at day 70 ( $n 2$ ))

\begin{tabular}{|c|c|c|c|c|c|c|c|c|c|c|c|c|c|c|c|c|c|c|c|c|}
\hline \multirow[b]{3}{*}{ Fatty acids } & \multicolumn{10}{|c|}{ Day 70} & \multicolumn{10}{|c|}{ Day 96} \\
\hline & \multicolumn{2}{|c|}{ so } & \multicolumn{2}{|c|}{ LO } & \multicolumn{2}{|l|}{ FO } & \multicolumn{2}{|c|}{ SO/LO } & \multicolumn{2}{|c|}{ SO/FO } & \multicolumn{2}{|c|}{ so } & \multicolumn{2}{|l|}{ LO } & \multicolumn{2}{|l|}{ FO } & \multicolumn{2}{|c|}{ SO/LO } & \multicolumn{2}{|c|}{ SO/FO } \\
\hline & Mean & SEM & Mean & SEM & Mean & SEM & Mean & SEM & Mean & SEM & Mean & SEM & Mean & SEM & Mean & SEM & Mean & SEM & Mean & SEM \\
\hline $14: 0$ & $2 \cdot 96^{\mathrm{c}}$ & 0.08 & $2 \cdot 32^{d}$ & 0.0 & $7 \cdot 19^{a}$ & 0.08 & $2 \cdot 77^{\mathrm{c}}$ & 0.09 & $4.45^{\mathrm{b}}$ & 0.00 & $2.53^{r}$ & 0.09 & $2 \cdot 74^{r}$ & 0.06 & $7.53^{p}$ & 0.03 & $2.53^{r}$ & 0.06 & $6.52^{q}$ & 0.13 \\
\hline $16: 0$ & $30 \cdot 22^{b}$ & 0.90 & $32 \cdot 71^{\mathrm{b}}$ & 1.38 & $40 \cdot 46^{\mathrm{a}}$ & 0.54 & $32 \cdot 04^{b}$ & 1.31 & $33 \cdot 13^{\mathrm{b}}$ & 0.26 & $28.53^{\mathrm{s}}$ & 0.53 & $39.06^{q}$ & 0.69 & $45 \cdot 01^{p}$ & 0.25 & $35 \cdot 19^{r}$ & 0.54 & $41.31^{q}$ & 0.64 \\
\hline $18: 0$ & $8.65^{\mathrm{b}}$ & 0.26 & $10 \cdot 78^{a}$ & 0.53 & $8.96^{\mathrm{b}}$ & 0.16 & $9 \cdot 68^{\mathrm{a}, \mathrm{b}}$ & 0.38 & $8.05^{\mathrm{b}}$ & 0.01 & $8.99^{\mathrm{s}}$ & 0.13 & $12 \cdot 98^{p}$ & 0.24 & $9.96^{r}$ & 0.09 & $11.52^{\mathrm{q}}$ & 0.17 & $9 \cdot 26^{\mathrm{s}}$ & 0.08 \\
\hline $16: 1 n-7$ & $9.60^{b, c}$ & 0.43 & $9 \cdot 37^{\mathrm{c}}$ & 0.49 & $16 \cdot 20^{\mathrm{a}}$ & 0.26 & $9 \cdot 39^{\mathrm{b}, \mathrm{c}}$ & 0.48 & $11.58^{\mathrm{b}}$ & 0.08 & $8 \cdot 31^{r}$ & 0.18 & $11.54^{q}$ & 0.43 & $17.92^{\mathrm{p}}$ & 0.32 & $10 \cdot 33^{9}$ & 0.47 & $15.91^{p}$ & 0.43 \\
\hline $18: 1 n-7$ & $3 \cdot 64^{\mathrm{c}}$ & 0.16 & $3.34^{c}$ & 0.22 & $6 \cdot 51^{a}$ & 0.09 & $3.61^{\mathrm{C}}$ & 0.10 & $4.66^{\mathrm{b}}$ & 0.02 & $3.57^{s}$ & 0.13 & $4.04^{r}$ & 0.11 & $7.52^{\mathrm{p}}$ & 0.09 & $3 \cdot 92^{r, s}$ & 0.06 & $6.67^{9}$ & 0.08 \\
\hline $18: 1 n-9$ & $120 \cdot 29^{\mathrm{a}}$ & 4.53 & $58 \cdot 29^{c}$ & 2.85 & $50 \cdot 86^{c}$ & 0.80 & $98 \cdot 20^{\mathrm{b}}$ & $4 \cdot 17$ & $87 \cdot 13^{\mathrm{b}}$ & 0.50 & $118 \cdot 16^{p}$ & 1.61 & $69 \cdot 65^{r}$ & 1.22 & $57 \cdot 23^{\mathrm{s}}$ & 0.62 & $75 \cdot 03^{q}$ & 0.17 & $65 \cdot 71^{r}$ & 0.66 \\
\hline $20: 1 n-9$ & $4 \cdot 36^{c}$ & 0.14 & $2 \cdot 11^{\mathrm{e}}$ & 0.16 & $9.66^{\mathrm{a}}$ & 0.17 & $3.57^{\mathrm{d}}$ & 0.08 & $6 \cdot 14^{\mathrm{b}}$ & 0.03 & $4 \cdot 60^{r}$ & 0.12 & $2 \cdot 41^{\mathrm{s}}$ & 0.09 & $10.88^{p}$ & 0.19 & $2.55^{\mathrm{s}}$ & 0.06 & $9.55^{\mathrm{q}}$ & 0.21 \\
\hline $18: 2 n-6$ & $24.56^{c}$ & 0.81 & $33.88^{\mathrm{a}}$ & 1.01 & $22 \cdot 32^{c}$ & 0.31 & $29 \cdot 14^{a, b}$ & 0.91 & $22 \cdot 97^{\mathrm{C}}$ & 0.13 & $24.43^{r}$ & 0.38 & $38.36^{p}$ & 0.42 & $24.68^{r}$ & 0.34 & $35.84^{9}$ & 0.39 & $24 \cdot 75^{r}$ & 0.45 \\
\hline $18: 3 n-6$ & $2 \cdot 68^{\mathrm{a}}$ & 0.16 & $1.27^{\mathrm{c}}$ & 0.05 & $0.62^{d}$ & 0.01 & $2 \cdot 18^{\mathrm{b}}$ & 0.06 & $1.98^{\mathrm{b}}$ & 0.07 & $2 \cdot 39^{p}$ & 0.02 & $1.22^{r}$ & 0.01 & $0.47^{t}$ & 0.02 & $1.50^{9}$ & 0.04 & $0.85^{\mathrm{s}}$ & 0.01 \\
\hline $20: 2 n-6$ & $1.32^{c}$ & 0.04 & $1.71^{\mathrm{a}}$ & 0.09 & $1.58^{\mathrm{a}, \mathrm{b}}$ & 0.00 & $1.49^{\mathrm{a}, \mathrm{b}, \mathrm{c}}$ & 0.03 & $1.42^{b, c}$ & 0.05 & $1.39^{\mathrm{s}}$ & 0.03 & $2 \cdot 04^{p}$ & 0.01 & $1.83^{q, r}$ & 0.02 & $1.88^{q}$ & 0.02 & $1.74^{r}$ & 0.03 \\
\hline $20: 3 n-6$ & $2 \cdot 15^{\mathrm{a}}$ & 0.17 & $1.66^{\mathrm{b}}$ & 0.10 & $0.98^{\mathrm{C}}$ & 0.02 & $2 \cdot 07^{\mathrm{a}, \mathrm{b}}$ & 0.06 & $1.67^{\mathrm{a}, \mathrm{b}}$ & 0.03 & $2 \cdot 15^{\mathrm{p}}$ & 0.04 & $1.83^{9}$ & 0.05 & $1.02^{\mathrm{s}}$ & 0.02 & $1.85^{\mathrm{q}}$ & 0.02 & $1.25^{r}$ & 0.01 \\
\hline $20: 4 n-6$ & $3 \cdot 29^{a}$ & 0.10 & $0.96^{\mathrm{c}}$ & 0.06 & $0.97^{c}$ & 0.02 & $2.57^{\mathrm{b}}$ & 0.10 & $2 \cdot 46^{\mathrm{b}}$ & 0.07 & $3.42^{\mathrm{p}}$ & 0.03 & $1 \cdot 16^{r}$ & 0.02 & $1 \cdot 13^{r}$ & 0.02 & $1.58^{q}$ & 0.01 & $1.51^{q}$ & 0.02 \\
\hline $22: 4 n-6$ & $0.46^{a}$ & 0.01 & $0.09^{c}$ & 0.01 & $0.08^{\mathrm{c}}$ & 0.00 & $0.33^{\mathrm{b}}$ & 0.01 & $0.30^{\mathrm{b}}$ & 0.01 & $0.46^{\mathrm{p}}$ & 0.02 & $0.09^{r}$ & 0.01 & $0.10^{r}$ & 0.00 & $0.15^{\mathrm{q}}$ & 0.01 & $0.16^{q}$ & 0.01 \\
\hline $22: 5 n-6$ & $3.08^{a}$ & 0.07 & $0.65^{c}$ & 0.08 & $0.69^{c}$ & 0.05 & $2 \cdot 22^{b}$ & 0.08 & $2.37^{\mathrm{b}}$ & 0.14 & $3.60^{p}$ & 0.08 & $0.20^{\mathrm{s}}$ & 0.01 & $0.33^{r}$ & 0.01 & $0.70^{q}$ & 0.04 & $0.83^{9}$ & 0.03 \\
\hline $18: 3 n-3$ & $0.45^{d}$ & 0.07 & $38.37^{a}$ & 0.89 & $1.91^{\mathrm{C}}$ & 0.03 & $15.94^{\mathrm{b}}$ & 0.32 & $1.44^{\mathrm{C}}$ & 0.17 & $0.51^{\mathrm{s}}$ & 0.09 & $38.75^{p}$ & 1.04 & $2.05^{r}$ & 0.06 & $31 \cdot 26^{q}$ & 1.07 & $1.85^{r}$ & 0.09 \\
\hline $18: 4 n-3$ & $0.22^{\mathrm{e}}$ & 0.01 & $4 \cdot 94^{a}$ & 0.05 & $1.25^{\mathrm{C}}$ & 0.01 & $1.99^{b}$ & 0.07 & $0.70^{d}$ & 0.03 & $0.20^{s}$ & 0.02 & $4.76^{p}$ & 0.04 & $1.34^{r}$ & 0.04 & $3.89^{9}$ & 0.17 & $1 \cdot 13^{r}$ & 0.03 \\
\hline $20: 3 n-3$ & $0.01^{\mathrm{e}}$ & 0.00 & $1.84^{\mathrm{a}}$ & 0.07 & $0.26^{c}$ & 0.01 & $0.76^{\mathrm{b}}$ & 0.01 & $0.13^{d}$ & 0.00 & $0.01^{r}$ & 0.01 & $2 \cdot 12^{\mathrm{p}}$ & 0.08 & $0.33^{9}$ & 0.02 & $1.72^{\mathrm{p}}$ & 0.08 & $0.28^{q}$ & 0.04 \\
\hline $20: 4 n-3$ & $0.37^{c}$ & 0.11 & $2 \cdot 27^{\mathrm{a}}$ & 0.24 & $1.35^{\mathrm{b}}$ & 0.04 & $1 \cdot 15^{\mathrm{b}}$ & 0.05 & $1.15^{\mathrm{b}}$ & 0.22 & $0.08^{t}$ & 0.01 & $2 \cdot 30^{p}$ & 0.07 & $1.36^{r}$ & 0.06 & $1.77^{q}$ & 0.01 & $1.04^{\mathrm{s}}$ & 0.03 \\
\hline $20: 5 n-3$ & $0.44^{d}$ & 0.01 & $2.07^{\mathrm{b}}$ & 0.11 & $4.48^{a}$ & 0.09 & $1.17^{\mathrm{C}}$ & 0.03 & $2 \cdot 13^{\mathrm{b}}$ & 0.02 & $0.26^{t}$ & 0.01 & $2 \cdot 39^{r}$ & 0.03 & $5 \cdot 22^{p}$ & 0.06 & $1.91^{\mathrm{s}}$ & 0.03 & $4.40^{9}$ & 0.11 \\
\hline $22: 5 n-3$ & $0.11^{d}$ & 0.01 & $0.86^{\mathrm{b}}$ & 0.09 & $1.47^{\mathrm{a}}$ & 0.04 & $0.44^{c}$ & 0.02 & $0.70^{\mathrm{b}}$ & 0.01 & $0.05^{t}$ & 0.01 & $0.97^{r}$ & 0.03 & $1.72^{p}$ & 0.03 & $0.73^{s}$ & 0.02 & $1.43^{\mathrm{q}}$ & 0.05 \\
\hline $22: 6 n-3$ & $1.99^{d}$ & 0.05 & $9.01^{\mathrm{b}}$ & 0.59 & $16 \cdot 96^{\mathrm{a}}$ & 0.45 & $5.57^{\mathrm{C}}$ & 0.24 & $8.32^{b}$ & 0.01 & $1.44^{\mathrm{t}}$ & 0.07 & $9.97^{r}$ & 0.17 & $19 \cdot 01^{p}$ & 0.38 & $8.42^{\mathrm{s}}$ & 0.17 & $16 \cdot 22^{q}$ & 0.53 \\
\hline Total & 223.09 & 7.91 & 219.76 & 9.00 & 197.81 & 2.98 & $228 \cdot 19$ & 8.40 & $205 \cdot 28$ & 0.01 & $217 \cdot 47^{r}$ & 2.93 & $250.05^{p}$ & 3.28 & $220.29^{r}$ & 1.94 & $236.01^{q}$ & 2.51 & $215 \cdot 80^{r}$ & 2.51 \\
\hline$\Sigma$ SFA $^{*}$ & $43.01^{\mathrm{b}}$ & 1.28 & $46 \cdot 32^{\mathrm{b}}$ & 1.99 & $57 \cdot 12^{\mathrm{a}}$ & 0.77 & $45.44^{\mathrm{b}}$ & 1.85 & $46.50^{\mathrm{b}}$ & 0.27 & $41.43^{\mathrm{s}}$ & 0.76 & $55.42^{\mathrm{q}}$ & 0.89 & $63 \cdot 11^{p}$ & 0.37 & $50.09^{r}$ & 0.51 & $57.78^{q}$ & 0.83 \\
\hline ¿MUFA $†$ & $138.93^{\mathrm{a}}$ & $5 \cdot 26$ & $73.86^{c}$ & 3.79 & $85 \cdot 76^{c}$ & 1.30 & $115 \cdot 72^{b}$ & 4.88 & $111.02^{\mathrm{b}}$ & 0.65 & $135.63^{p}$ & 1.99 & $88.48^{\mathrm{s}}$ & 1.51 & $96 \cdot 58^{q, r}$ & $1 \cdot 11$ & $92 \cdot 72^{r, s}$ & 0.42 & $100.59^{9}$ & 1.00 \\
\hline$\Sigma C 18 n-6$ PUFA & $27 \cdot 25^{\mathrm{b}}$ & 0.97 & $35 \cdot 16^{a}$ & 1.05 & $22.94^{c}$ & 0.32 & $31.32^{\mathrm{a}}$ & 0.95 & $24.95^{b, c}$ & 0.06 & $26 \cdot 81^{r}$ & 0.36 & $39.58^{p}$ & 0.43 & $25 \cdot 15^{r}$ & 0.33 & $37.35^{9}$ & 0.42 & $25 \cdot 60^{r}$ & 0.46 \\
\hline$\Sigma n-6$ LC-PUFA§ & $10 \cdot 29^{a}$ & 0.40 & $5.07^{\mathrm{C}}$ & 0.32 & $4 \cdot 30^{\mathrm{c}}$ & 0.06 & $8.68^{b}$ & 0.25 & $8 \cdot 22^{\mathrm{b}}$ & 0.02 & $11.02^{\mathrm{p}}$ & 0.11 & $5 \cdot 31^{r}$ & 0.03 & $4 \cdot 41^{\mathrm{s}}$ & 0.03 & $6 \cdot 16^{9}$ & 0.07 & $5.49^{r}$ & 0.06 \\
\hline$\sum$ C18 $n$-3 PUFAll & $0.68^{\mathrm{e}}$ & 0.08 & $43.32^{\mathrm{a}}$ & 0.94 & $3 \cdot 17^{\mathrm{c}}$ & 0.03 & $17.94^{b}$ & 0.36 & $2 \cdot 14^{d}$ & 0.20 & $0.71^{\mathrm{s}}$ & 0.10 & $43.51^{p}$ & 1.03 & $3.39^{r}$ & 0.06 & $35 \cdot 15^{q}$ & 1.24 & $2 \cdot 98^{r}$ & 0.07 \\
\hline$\Sigma n-3$ LC-PUFAT & $2.93^{\mathrm{e}}$ & 0.18 & $16 \cdot 04^{\mathrm{b}}$ & 1.08 & $24.53^{\mathrm{a}}$ & 0.62 & $9 \cdot 10^{d}$ & 0.25 & $12 \cdot 44^{c}$ & 0.26 & $1.86^{t}$ & 0.10 & $17 \cdot 75^{r}$ & 0.17 & $27.65^{p}$ & 0.52 & $14.54^{\mathrm{s}}$ & 0.11 & $23 \cdot 36^{q}$ & 0.64 \\
\hline$n-3: n-6^{\star \star}$ & $0.10^{\mathrm{e}}$ & 0.00 & $1.48^{\mathrm{a}}$ & 0.01 & $1.02^{\mathrm{b}}$ & 0.01 & $0.68^{\mathrm{C}}$ & 0.01 & $0.44^{d}$ & 0.02 & $0.07^{t}$ & 0.01 & $1.36^{p}$ & 0.01 & $1.05^{r}$ & 0.01 & $1.14^{\mathrm{q}}$ & 0.02 & $0.85^{\mathrm{s}}$ & 0.00 \\
\hline$n-3: n-6$ LC-PUFAt & $0.28^{\mathrm{e}}$ & 0.02 & $3.16^{\mathrm{b}}$ & 0.06 & $5 \cdot 71^{a}$ & 0.11 & $1.05^{\mathrm{d}}$ & 0.01 & $1.51^{\mathrm{C}}$ & 0.04 & $0.17^{\mathrm{t}}$ & 0.01 & $3.34^{r}$ & 0.02 & $6.27^{p}$ & 0.11 & $2.36^{\mathrm{s}}$ & 0.01 & $4.25^{\mathrm{q}}$ & 0.08 \\
\hline
\end{tabular}

LO, linseed oil-based diet; SO/LO, SO until day 60 and then LO from days 61-96; LC-PUFA, long-chain PUFA ( $\geq 20 \mathrm{C}$ ).

a,b,c,d,e For day 70 and $\mathrm{p}, \mathrm{q}, \mathrm{r}, \mathrm{s,t}$ for day 96 : mean values within a row with unlike superscript letters were significantly different (Tukey's post hoc test on square root transformed values for each sampling day, a $5 \%$ ). * Sum of SFA, includes 20:0, 22:0 and 24:0.

† Sum of MUFA, includes $14: 1 n-5,22: 1 n-9$ and $24: 1 n-9$

₹ Sum of $n-6$ PUFA with $18 \mathrm{C}$.

$\S$ Sum of $n-6$ LC-PUFA with $20 \mathrm{C}$ and $22 \mathrm{C}$

II Sum of $n-3$ PUFA with $18 \mathrm{C}$.

I Sum of $n-3$ LC-PUFA with 20C and 22C.

** Ratio of total $n$-3 PUFA:total $n$-6 PUFA.

t† Ratio of $n-3$ LC-PUFA: $n-6$ LC-PUFA. 
Table 6. Fatty acid metabolism ( $\mathrm{nmol} / \mathrm{g}$ per $\mathrm{d}$ ), deduced by the whole body fatty acid balance method, of rainbow trout held on varying dietary lipid source diets for a 60-d pre-experimental feeding period (Mean values with their standard errors; $n 3$ )

\begin{tabular}{|c|c|c|c|c|c|c|}
\hline & \multicolumn{2}{|c|}{ so } & \multicolumn{2}{|c|}{ LO } & \multicolumn{2}{|c|}{$\mathrm{FO}$} \\
\hline & Mean & SEM & Mean & SEM & Mean & SEM \\
\hline \multicolumn{7}{|l|}{ SFA and MUFA } \\
\hline$\beta$-Oxidation & $223.5^{\mathrm{a}}$ & $26 \cdot 4$ & $4.7^{\mathrm{b}}$ & 0.8 & $26 \cdot 0^{\mathrm{b}}$ & $10 \cdot 1$ \\
\hline Elongation & $1865 \cdot 3^{\mathrm{b}}$ & 10.4 & $3850 \cdot 3^{a}$ & 191.0 & $3205.0^{\mathrm{a}}$ & 225.6 \\
\hline$\Delta-9$ desaturation & $286 \cdot 6^{c}$ & 3.6 & $921 \cdot 1^{\mathrm{a}}$ & 48.4 & $722 \cdot 3^{b}$ & 49.0 \\
\hline \multicolumn{7}{|l|}{$n-6$ PUFA } \\
\hline$\beta$-Oxidation & $173.0^{\mathrm{a}}$ & 8.1 & $179 \cdot 2^{\mathrm{a}}$ & $26 \cdot 0$ & $4 \cdot 8^{b}$ & 4.8 \\
\hline Elongation & $379 \cdot 1^{\mathrm{a}}$ & 5.4 & $111.6^{\mathrm{b}}$ & $2 \cdot 7$ & $58.5^{\mathrm{c}}$ & $2 \cdot 6$ \\
\hline $18: 3 n-6$ to $20: 3 n-6$ & $205 \cdot 9^{\mathrm{a}}$ & 1.7 & $66.0^{\mathrm{b}}$ & $2 \cdot 1$ & $31.2^{\mathrm{c}}$ & 0.7 \\
\hline $20: 4 n-6$ to $22: 4 n-6$ & $77 \cdot 1^{\mathrm{a}}$ & 1.6 & $5 \cdot 4^{\mathrm{b}}$ & 0.2 & $2 \cdot 1^{\mathrm{c}}$ & 0.4 \\
\hline $22: 4 n-6$ to $24: 4 n-6$ & $68.4^{\mathrm{a}}$ & 1.4 & $4 \cdot 2^{\mathrm{b}}$ & 0.3 & $0.5^{\mathrm{c}}$ & 0.2 \\
\hline$\Delta-5$ desaturation & $153 \cdot 1^{\mathrm{a}}$ & 1.3 & $27 \cdot 4^{\mathrm{b}}$ & 0.9 & $10 \cdot 2^{\mathrm{c}}$ & 0.5 \\
\hline$\Delta-6$ desaturation & $344 \cdot 0^{\mathrm{a}}$ & $2 \cdot 0$ & $92 \cdot 2^{\mathrm{b}}$ & 3.6 & $40 \cdot 2^{c}$ & 0.9 \\
\hline $18: 2 n-6$ to $18: 3 n-6$ & $275 \cdot 6^{\mathrm{a}}$ & 1.0 & $88.0^{\mathrm{b}}$ & 3.6 & $39.6^{\mathrm{C}}$ & 0.7 \\
\hline $24: 4 n-6$ to $24: 5 n-6$ & $68 \cdot 4^{\mathrm{a}}$ & 1.4 & $4 \cdot 2^{\mathrm{b}}$ & 0.3 & $0.5^{\mathrm{c}}$ & 0.2 \\
\hline \multicolumn{7}{|l|}{$n-3$ PUFA } \\
\hline$\beta$-Oxidation & $38 \cdot 4^{\mathrm{c}}$ & 0.8 & $476 \cdot 2^{\mathrm{a}}$ & $41 \cdot 1$ & $198.9^{b}$ & $13 \cdot 2$ \\
\hline Elongation & $37.8^{\mathrm{c}}$ & $2 \cdot 0$ & $761.9^{\mathrm{a}}$ & 19.3 & $108 \cdot 0^{\mathrm{b}}$ & $22 \cdot 4$ \\
\hline $18: 4 n-3$ to $20: 4 n-3$ & $10 \cdot 1^{\mathrm{b}}$ & 1.1 & $309 \cdot 7^{\mathrm{a}}$ & 7.8 & $0.0^{c}$ & 0.0 \\
\hline $20: 5 n-3$ to $22: 5 n-3$ & $13 \cdot 7^{\mathrm{c}}$ & 0.5 & $215 \cdot 7^{\mathrm{a}}$ & 4.8 & $43 \cdot 6^{b, c}$ & 11.8 \\
\hline $22: 5 n-3$ to $24: 5 n-3$ & $14 \cdot 0^{c}$ & 0.4 & $200 \cdot 6^{\mathrm{a}}$ & 4.6 & $60 \cdot 6^{\mathrm{b}}$ & 11.0 \\
\hline$\Delta-5$ desaturation & $11 \cdot 0^{\mathrm{b}}$ & 1.0 & $260 \cdot 5^{\mathrm{a}}$ & $5 \cdot 8$ & $0^{c}$ & 0 \\
\hline$\Delta-6$ desaturation & $28 \cdot 4^{\mathrm{C}}$ & 1.3 & $637.9^{a}$ & $16 \cdot 7$ & $60 \cdot 6^{\mathrm{b}}$ & 11.0 \\
\hline $18: 3 n-3$ to $18: 4 n-3$ & $14 \cdot 4^{\mathrm{b}}$ & 1.0 & $437 \cdot 3^{\mathrm{a}}$ & $13 \cdot 2$ & $0.0^{c}$ & 0.0 \\
\hline $24: 5 n-3$ to $24: 6 n-3$ & $14 \cdot 0^{c}$ & 0.4 & $200 \cdot 6^{\mathrm{a}}$ & 4.6 & $60 \cdot 6^{\mathrm{b}}$ & 11.0 \\
\hline \multicolumn{7}{|l|}{$n-6$ and $n-3$ PUFA } \\
\hline$\Delta-5$ desaturation & $164 \cdot 1^{\mathrm{b}}$ & $2 \cdot 2$ & $287.9^{a}$ & $6 \cdot 7$ & $10 \cdot 2^{c}$ & 0.5 \\
\hline$\Delta-6$ desaturation & $372 \cdot 5^{\mathrm{b}}$ & 3.3 & $730 \cdot 1^{a}$ & $20 \cdot 2$ & $100 \cdot 8^{c}$ & 11.9 \\
\hline
\end{tabular}

subsequently reverted to a diet rich in ALA or rich in EPA and DHA, for a 36-d experimental period. As controls, three other fish groups received SO, LO and FO throughout the 96-d feeding trial.

\section{Fish growth and proximate composition}

A negative impact of SO was observed on fish growth performance in comparison to fish fed on LO or FO for $96 \mathrm{~d}$. These results contrast with previous studies adding regular LA-rich sunflower oil or fish oil as only dietary lipid source in diets of Atlantic salmon ${ }^{(44)}$ and rainbow trout ${ }^{(19)}$ where no difference in fish growth and proximate composition between the two fish groups was reported. However, these studies were conducted on fish of a larger size and used fishmeal as the dietary protein source, which undoubtedly provided $n$-3 LC-PUFA to the diet, up to a level that might potentially meet the requirements for these health promoting nutrients. The fatty acid requirements of rainbow trout are $1 \%$ ALA, $1 \%$ LA and/or $0.5 \% n-3$ LC-PUFA in their diet $(\mathrm{DM})^{(5)}$. The present lower growth of SO-fed fish was certainly due to the deficiency in essential ALA and n-3 LC-PUFA, as well as to an interconnected reduced feed intake. In contrast with the present results on SO fish, and in accordance with previous studies ${ }^{(14,18,45,46)}$, feeding LO for $96 \mathrm{~d}$ had no impact on fish growth. The replacement of SO by LO or FO for the 36-d experimental period significantly improved the growth of fish initially fed on SO. Indeed, the FE were higher in
SO/LO and SO/FO fish groups as compared with the SO fish group and were similar to those observed in LO and FO fish groups, respectively. The present results demonstrate the rapid capacity of rainbow trout to cope with a change in dietary source. Turchini et al. ${ }^{(47)}$ previously reported enhanced growth, termed 'lipo-compensatory growth', of Murray cod fed a plantderived oil diet and then a fish oil diet in comparison to fish fed a fish oil diet throughout. Similar observations were also reported in Atlantic salmon when shifted from rapeseed oil to a fish oil diet ${ }^{(48)}$ and for red seabream fed a soyabean oil diet for 3 months and then a fish oil diet for $32 \mathrm{~d}^{(27)}$.

\section{Fish fatty acid composition}

At the end of the pre-experimental period (day 60), a high depletion in C18 n-3 PUFA and n-3 LC-PUFA was observed in fish of the SO treatment. This led to conclude on the efficiency of the pre-experimental period duration and in turn on the adequacy of the study design for evaluating the effects of the body $n$-3 PUFA depletion on the fish fatty acid bioconversion capacity. Interestingly, the $n-3$ PUFA depletion continued throughout the rest of the feeding trial for the SO treatment, following a decreasing exponential curve, as highlighted at days 70 and 96 . Several studies ${ }^{(14,19,22,23,44)}$ have previously reported that the fatty acid composition of fish reflects that of the dietary lipid source. Similarly, in the present study, fish fed on the $18: 1 n$-9-rich SO were the richest in $18: 1 n$-9, whereas fish fed 
Table 7. Fatty acid metabolism (nmol/g per $\mathrm{d}$ ), deduced by the whole body fatty acid balance method, of rainbow trout held on varying dietary lipid source diets for a 36-d experimental period after a 60-d pre-experimental period

(Mean values with their standard errors; $n 3$ )

\begin{tabular}{|c|c|c|c|c|c|c|c|c|c|c|}
\hline & \multicolumn{2}{|c|}{ so } & \multicolumn{2}{|c|}{ LO } & \multicolumn{2}{|c|}{ FO } & \multicolumn{2}{|c|}{ SO/LO } & \multicolumn{2}{|c|}{ SO/FO } \\
\hline & Mean & SEM & Mean & SEM & Mean & SEM & Mean & SEM & Mean & SEM \\
\hline \multicolumn{11}{|l|}{ SFA and MUFA } \\
\hline$\beta$-Oxidation & $1545 \cdot 9^{a}$ & $128 \cdot 6$ & $4 \cdot 6^{c}$ & 0.8 & $10 \cdot 3^{\mathrm{b}}$ & 1.4 & $5 \cdot 1^{\mathrm{c}}$ & 0.8 & $12 \cdot 5^{\mathrm{b}}$ & 0.4 \\
\hline Elongation & $1006 \cdot 4^{c}$ & $100 \cdot 6$ & $6824 \cdot 6^{\mathrm{a}}$ & 361.9 & $5580 \cdot 6^{a, b}$ & $359 \cdot 3$ & $4889 \cdot 1^{\mathrm{b}}$ & $272 \cdot 2$ & $4520 \cdot 6^{b}$ & $243 \cdot 8$ \\
\hline$\Delta-9$ desaturation & $160 \cdot 0^{c}$ & 7.9 & $1582 \cdot 2$ & $85 \cdot 3$ & $1234 \cdot 9^{\mathrm{b}}$ & 88.9 & $1078 \cdot 9^{b}$ & $67 \cdot 2$ & $944 \cdot 9^{b}$ & 60.3 \\
\hline \multicolumn{11}{|l|}{$n-6$ PUFA } \\
\hline$\beta$-Oxidation & $548 \cdot 7^{\mathrm{a}}$ & $26 \cdot 4$ & $159 \cdot 3^{\mathrm{b}}$ & $27 \cdot 0$ & $0.0^{c}$ & 0.0 & $212 \cdot 1^{\mathrm{b}}$ & $40 \cdot 4$ & $1.8^{\mathrm{C}}$ & 0.3 \\
\hline Elongation & $348.9^{\mathrm{a}}$ & $7 \cdot 7$ & $162 \cdot 3^{b}$ & 2.9 & $82 \cdot 9^{\mathrm{d}}$ & 3.8 & $134.4^{c}$ & 4.4 & $78.7^{d}$ & $1 \cdot 2$ \\
\hline $18: 3 n-6$ to $20: 3 n-6$ & $180 \cdot 3^{\mathrm{a}}$ & 3.4 & $91 \cdot 3^{\mathrm{b}}$ & $2 \cdot 4$ & $40 \cdot 3^{\mathrm{d}}$ & 1.7 & $76 \cdot 7^{\mathrm{c}}$ & $2 \cdot 7$ & $36 \cdot 4^{d}$ & 1.0 \\
\hline $20: 4 n-6$ to $22: 4 n-6$ & $74.7^{\mathrm{a}}$ & $2 \cdot 7$ & $7 \cdot 6^{\mathrm{b}}$ & 0.4 & $3.4^{\mathrm{c}}$ & 0.3 & $2 \cdot 3^{c}$ & 0.7 & $2 \cdot 6^{c}$ & 0.3 \\
\hline $22: 4 n-6$ to $24: 4 n-6$ & $66 \cdot 6^{\mathrm{a}}$ & $2 \cdot 2$ & $5 \cdot 0^{\mathrm{b}}$ & 0.2 & $0.7^{\mathrm{c}}$ & 0.2 & $0.3^{\mathrm{c}, \mathrm{d}}$ & 0.3 & $0.0^{\mathrm{d}}$ & 0.0 \\
\hline$\Delta-5$ desaturation & $141.5^{\mathrm{a}}$ & 3.0 & $41.3^{\mathrm{b}}$ & 1.2 & $16 \cdot 5^{d}$ & 0.4 & $31 \cdot 2^{\mathrm{c}}$ & 1.2 & $12 \cdot 6^{\mathrm{e}}$ & 0.2 \\
\hline$\Delta-6$ desaturation & $293.1^{\mathrm{a}}$ & 5.9 & $120 \cdot 6^{\mathrm{b}}$ & 4.3 & $52 \cdot 4^{d}$ & 2.5 & $98 \cdot 8^{\mathrm{c}}$ & 4.8 & $43 \cdot 5^{d}$ & 1.4 \\
\hline $18: 2 n-6$ to $18: 3 n-6$ & $226 \cdot 4^{\mathrm{a}}$ & 3.7 & $115 \cdot 6^{\mathrm{b}}$ & 4.1 & $51 \cdot 7^{d}$ & $2 \cdot 2$ & $98.5^{\mathrm{c}}$ & 4.6 & $43.5^{\mathrm{d}}$ & 1.4 \\
\hline $24: 4 n-6$ to $24: 5 n-6$ & $66 \cdot 6^{\mathrm{a}}$ & $2 \cdot 2$ & $5 \cdot 0^{\mathrm{b}}$ & 0.2 & $0.7^{\mathrm{c}}$ & 0.2 & $0.3^{\mathrm{c}, \mathrm{d}}$ & 0.3 & $0.0^{d}$ & 0.0 \\
\hline \multicolumn{11}{|l|}{$n-3$ PUFA } \\
\hline$\beta$-Oxidation & $47 \cdot 2^{\mathrm{C}}$ & 4.5 & $485 \cdot 3^{a}$ & $59 \cdot 3$ & $142 \cdot 4^{\mathrm{b}}$ & $15 \cdot 7$ & $496 \cdot 2^{\mathrm{a}}$ & $64 \cdot 6$ & $157 \cdot 7^{b}$ & 4.4 \\
\hline Elongation & $40 \cdot 5^{\mathrm{c}}$ & $6 \cdot 1$ & $1002 \cdot 7^{\mathrm{a}}$ & $26 \cdot 4$ & $239.4^{\mathrm{b}}$ & $25 \cdot 4$ & $1010 \cdot 9^{a}$ & $19 \cdot 1$ & $258 \cdot 1^{b}$ & 20.8 \\
\hline $18: 4 n-3$ to $20: 4 n-3$ & $15 \cdot 1^{\mathrm{b}}$ & $2 \cdot 3$ & $412 \cdot 0^{\mathrm{a}}$ & $9 \cdot 4$ & $3 \cdot 1^{\mathrm{c}}$ & 1.6 & $410 \cdot 4^{a}$ & $7 \cdot 2$ & $0.0^{c}$ & 0.0 \\
\hline $20: 5 n-3$ to $22: 5 n-3$ & $12 \cdot 4^{\mathrm{c}}$ & 1.8 & $279 \cdot 2^{\mathrm{a}}$ & $7 \cdot 9$ & $110 \cdot 9^{b}$ & $12 \cdot 4$ & $283 \cdot 1^{\mathrm{a}}$ & $6 \cdot 0$ & $119 \cdot 9^{b}$ & 11.4 \\
\hline $22: 5 n-3$ to $24: 5 n-3$ & $12 \cdot 6^{\mathrm{c}}$ & 1.8 & $253 \cdot 1^{a}$ & 7.5 & $123 \cdot 0^{\mathrm{b}}$ & 11.6 & $260 \cdot 1^{a}$ & 6.5 & $134 \cdot 6^{\mathrm{b}}$ & 11.0 \\
\hline$\Delta-5$ desaturation & $13 \cdot 4^{\mathrm{b}}$ & $2 \cdot 1$ & $346 \cdot 5^{\mathrm{a}}$ & 9.9 & $0.0^{c}$ & 0.0 & $347 \cdot 4^{\mathrm{a}}$ & $6 \cdot 4$ & $0.0^{c}$ & 0.0 \\
\hline$\Delta-6$ desaturation & $30 \cdot 2^{c}$ & 4.5 & $808 \cdot 6^{\mathrm{a}}$ & $19 \cdot 3$ & $123 \cdot 0^{\mathrm{b}}$ & 11.6 & $821 \cdot 7^{\mathrm{a}}$ & $17 \cdot 2$ & $134 \cdot 6^{\mathrm{b}}$ & 11.0 \\
\hline $18: 3 n-3$ to $18: 4 n-3$ & $17 \cdot 6^{\mathrm{b}}$ & $2 \cdot 7$ & $555.5^{\mathrm{a}}$ & $12 \cdot 1$ & $0.0^{c}$ & 0.0 & $561.5^{\mathrm{a}}$ & $12 \cdot 2$ & $0.0^{\mathrm{C}}$ & 0.0 \\
\hline $24: 5 n-3$ to $24: 6 n-3$ & $12 \cdot 6^{\mathrm{c}}$ & 1.8 & $253 \cdot 1^{\mathrm{a}}$ & 7.5 & $123 \cdot 0^{\mathrm{b}}$ & 11.6 & $260 \cdot 1^{\mathrm{a}}$ & 6.5 & $134 \cdot 6^{\mathrm{b}}$ & 11.0 \\
\hline \multicolumn{11}{|l|}{$n-6$ and $n-3$ PUFA } \\
\hline$\Delta-5$ desaturation & $154 \cdot 9^{b}$ & 3.0 & $387 \cdot 8^{a}$ & $10 \cdot 8$ & $16 \cdot 5^{\mathrm{c}}$ & 0.4 & $378 \cdot 6^{\mathrm{a}}$ & $7 \cdot 2$ & $12 \cdot 6^{\mathrm{c}}$ & 0.2 \\
\hline$\Delta-6$ desaturation & $323 \cdot 3^{b}$ & $5 \cdot 7$ & $929.2^{\mathrm{a}}$ & 23.4 & $175 \cdot 4^{c}$ & $12 \cdot 3$ & $920 \cdot 5^{a}$ & $21 \cdot 3$ & $178 \cdot 1^{c}$ & $10 \cdot 3$ \\
\hline
\end{tabular}

SO, sunflower oil-based diet; LO, linseed oil-based diet; FO, fish oil-based diet; SO/LO, SO until day 60 and then LO from days 61-96; SO/FO, SO until day 60 and then FO from days $61-96$.

a,b,c,d,e Mean values within a row with unlike superscript letters were significantly different (Tukey's post hoc test on square root transformed values, a $5 \%$ ).

on LO presented a high ALA concentration while those fed on FO had the largest EPA and DHA concentrations. Certain discrepancies with the dietary fatty acid profile were evident in fish samples. For example, despite an absence of dietary $n-6$ LC-PUFA, these fatty acids were the highest in fish of the SO treatment, pointing towards an active in vivo metabolism. This result contrasts with previously published work on Atlantic salmon fed a $100 \%$ LA-rich sunflower oil diet, where an increased 20:2n-6 concentration and decreased 20:4n-6 concentration were reported in comparison to fish fed a fish oil diet $^{(44)}$. However, the present result is in line with the results of a study on rainbow trout fed a $100 \%$ LA-rich sunflower oil diet in comparison to fish oil diet and linseed oil diet ${ }^{(19)}$. In similar fashion, fish fed on LO in the present study recorded the highest concentrations of $n-3$ PUFA fatty acid intermediates (18:4n-3, $20: 3 n-3$ and $20: 4 n-3)$, despite being absent from the diet. The same observation was previously reported in rainbow trout fed a linseed oil diet for $112 \mathrm{~d}$ as compared with fish fed on sunflower oil diet or fish oil diet ${ }^{(19)}$. As previously observed by numerous studies, the present observations highlight, first, the relatively high capacity of rainbow trout to endogenously convert dietary LA and ALA into $n-6$ and $n$ - 3 LC-PUFA, respectively, and second, the modulation of the fish bioconversion capacity induced by the dietary lipid source $e^{(9,14,17,19,20,22,31,49)}$. Indeed, more bioconverted products were reported along the $n-6$ pathway in fish fed on SO considering that LA was one of major fatty acids present as substrate and that dietary ALA was almost absent, as previously observed in European sea bass ${ }^{(31)}$. Conversely, more bioconverted products of the $n-3$ pathway were observed in fish fed on LO as LA was present to a lesser extent than ALA and also considering the initial affinity of enzymes towards the $n-3$ PUFA as compared with the $n-6$ PUFA family ${ }^{(14,15,49)}$. A high recovery rate in $n$ - 3 PUFA was observed for SO/LO and SO/FO fish at the end of the 36-d experimental period. Indeed, SO/LO and SO/FO fish recovered a fatty acid profile with $>80 \%$ of the C18 n-3 PUFA and n-3 LC-PUFA values observed in fish fed on LO and FO, respectively, for $96 \mathrm{~d}$. Interestingly, the transfer of Atlantic salmon previously fed a rapeseed oil diet for 50 weeks to a fish oil diet for 20 weeks also restored their EPA and DHA concentrations to $80 \%$ of the levels found in fish fed on a fish oil diet for 70 weeks $^{(22)}$. In European sea bass, $70 \%$ recovery in EPA and DHA was reported in the flesh of fish fed a $40 \%$ fish oil/ $60 \%$ plant-derived oil blend for 64 weeks and then a finishing fish oil diet for a further 20 weeks, in comparison with fish fed on fish oil throughout ${ }^{(26)}$. However, two notable differences are apparent between both of these studies and the present one. Indeed, the results of the previous studies were based on fillet data from harvestable size fish whereas the present recovery rates are based on whole body fatty acid composition of fish from 20 to $50 \mathrm{~g}$. Besides the recovery rates of $80 \%$ observed at the end of the experimental period, the 
Table 8. Fatty acid metabolism ( $\mathrm{nmol} / \mathrm{g}$ per d), deduced by the whole body fatty acid balance method, of rainbow trout held on varying dietary lipid source diets for a 10-d experimental period after a 60-d pre-experimental period

(Mean values with their standard errors; $n 3$ except sunflower oil-based diet (SO) until day 60 and then fish oil-based diet (FO) from days 61-96 (SO/FO) treatment $(n 2))$

\begin{tabular}{|c|c|c|c|c|c|c|c|c|c|c|}
\hline & \multicolumn{2}{|c|}{ so } & \multicolumn{2}{|c|}{ LO } & \multicolumn{2}{|c|}{ FO } & \multicolumn{2}{|c|}{ SO/LO } & \multicolumn{2}{|c|}{ SO/FO } \\
\hline & Mean & SEM & Mean & SEM & Mean & SEM & Mean & SEM & Mean & SEM \\
\hline \multicolumn{11}{|l|}{ SFA and MUFA } \\
\hline$\beta$-Oxidation & 1101.5 & 421.5 & $20 \cdot 6$ & $7 \cdot 0$ & 63.0 & 29.9 & 355.2 & 333.1 & $685 \cdot 1$ & 99.4 \\
\hline Elongation & 1994.9 & 374.3 & $6025 \cdot 3$ & 1511.3 & $6072 \cdot 1$ & 355.9 & $3045 \cdot 2$ & 964.3 & $1702 \cdot 3$ & $220 \cdot 8$ \\
\hline$\Delta-9$ desaturation & $273 \cdot 5^{\mathrm{b}}$ & 53.9 & $1354 \cdot 2^{\mathrm{a}}$ & 340.3 & $1281 \cdot 6^{\mathrm{a}}$ & $61 \cdot 8$ & $506 \cdot 5^{\mathrm{a}, \mathrm{b}}$ & 185.0 & $192.9^{b}$ & 9.8 \\
\hline \multicolumn{11}{|l|}{$n-6$ PUFA } \\
\hline$\beta$-Oxidation & $463 \cdot 6^{a}$ & 111.2 & $401 \cdot 2^{\mathrm{a}}$ & $118 \cdot 7$ & $12 \cdot 9^{b}$ & $12 \cdot 9$ & $454 \cdot 2^{a}$ & $135 \cdot 7$ & $200 \cdot 3^{a, b}$ & 43.0 \\
\hline Elongation & $372 \cdot 1^{\mathrm{a}}$ & 45.4 & $305 \cdot 6^{a, b}$ & $42 \cdot 0$ & $180 \cdot 0^{\mathrm{b}, \mathrm{c}}$ & $19 \cdot 0$ & $142 \cdot 6^{c}$ & $23 \cdot 4$ & $107 \cdot 3^{\mathrm{c}}$ & 34.5 \\
\hline $18: 3 n-6$ to $20: 3 n-6$ & $201 \cdot 4^{a}$ & 29.9 & $141 \cdot 5^{\mathrm{a}, \mathrm{b}}$ & $21 \cdot 3$ & $70 \cdot 4^{b, c}$ & $5 \cdot 0$ & $75 \cdot 2^{\mathrm{b}, \mathrm{c}}$ & $16 \cdot 4$ & $28.0^{C}$ & 9.8 \\
\hline $20: 4 n-6$ to $22: 4 n-6$ & $73 \cdot 2^{\mathrm{a}}$ & 6.5 & $50 \cdot 9^{\mathrm{a}, \mathrm{b}}$ & 7.9 & $35 \cdot 6^{a, b}$ & 5.5 & $8 \cdot 8^{\mathrm{C}}$ & $3 \cdot 2$ & $20 \cdot 8^{b, c}$ & $13 \cdot 3$ \\
\hline $22: 4 n-6$ to $24: 4 n-6$ & $61 \cdot 2$ & 5.4 & $46 \cdot 2$ & 7.3 & $32 \cdot 9$ & 4.9 & 4.0 & 2.5 & $17 \cdot 8$ & $14 \cdot 1$ \\
\hline$\Delta-5$ desaturation & $157.6^{\mathrm{a}}$ & $15 \cdot 8$ & $85 \cdot 0^{\mathrm{a}, \mathrm{b}}$ & $10 \cdot 6$ & $44 \cdot 4^{\mathrm{b}, \mathrm{c}}$ & 6.9 & $31 \cdot 7^{b, c}$ & $11 \cdot 8$ & $18 \cdot 9^{\mathrm{C}}$ & $10 \cdot 2$ \\
\hline$\Delta-6$ desaturation & $339 \cdot 3^{\mathrm{a}}$ & 51.3 & $225 \cdot 7^{\mathrm{a}, \mathrm{b}}$ & $36 \cdot 0$ & $136 \cdot 5^{\mathrm{b}, \mathrm{c}}$ & $10 \cdot 4$ & $96 \cdot 6^{b, c}$ & $22 \cdot 0$ & $50 \cdot 8^{\mathrm{C}}$ & $33 \cdot 3$ \\
\hline $18: 2 n-6$ to $18: 3 n-6$ & $278.0^{\mathrm{a}}$ & $45 \cdot 8$ & $179 \cdot 5^{a, b}$ & 30.7 & $103 \cdot 6^{\mathrm{b}, \mathrm{c}}$ & $5 \cdot 6$ & $92 \cdot 7^{b, c}$ & $19 \cdot 7$ & $32 \cdot 9^{\mathrm{C}}$ & $19 \cdot 2$ \\
\hline $24: 4 n-6$ to $24: 5 n-6$ & $61 \cdot 2$ & 5.4 & $46 \cdot 2$ & $7 \cdot 3$ & $32 \cdot 9$ & 4.9 & 4.0 & 2.5 & $17 \cdot 8$ & $14 \cdot 1$ \\
\hline \multicolumn{11}{|l|}{$n-3$ PUFA } \\
\hline$\beta$-Oxidation & $38 \cdot 8$ & $15 \cdot 6$ & 439.5 & $162 \cdot 4$ & 302.5 & $57 \cdot 0$ & 360.2 & $80 \cdot 0$ & 186.5 & $44 \cdot 3$ \\
\hline Elongation & $58 \cdot 4^{\mathrm{b}}$ & $30 \cdot 3$ & $979 \cdot 4^{\mathrm{a}}$ & 208.9 & $141.0^{\mathrm{b}}$ & $62 \cdot 3$ & $1221 \cdot 1^{\mathrm{a}}$ & 63.9 & $252 \cdot 2^{\mathrm{b}}$ & 46.4 \\
\hline $18: 4 n-3$ to $20: 4 n-3$ & $38.4^{\mathrm{b}}$ & $18 \cdot 2$ & $414 \cdot 9^{\mathrm{a}}$ & $95 \cdot 3$ & $22 \cdot 4^{\mathrm{b}}$ & 2.6 & $509 \cdot 3^{\mathrm{a}}$ & $22 \cdot 4$ & $55 \cdot 2^{\mathrm{b}}$ & $21 \cdot 2$ \\
\hline $20: 5 n-3$ to $22: 5 n-3$ & 9.2 & $6 \cdot 4$ & $262 \cdot 7$ & 60.7 & $53 \cdot 2$ & $27 \cdot 1$ & 338.8 & $21 \cdot 8$ & $86 \cdot 6$ & $13 \cdot 8$ \\
\hline $22: 5 n-3$ to $24: 5 n-3$ & 9.4 & $5 \cdot 8$ & $230 \cdot 1$ & 51.9 & 65.4 & 33.1 & 310.5 & $20 \cdot 4$ & $105 \cdot 7$ & 11.4 \\
\hline$\Delta-5$ desaturation & $9.7^{\mathrm{b}}$ & 8.1 & $323.4^{\mathrm{a}}$ & 74.3 & $0.0^{b}$ & 0.0 & $409 \cdot 7^{\mathrm{a}}$ & 24.4 & $0.0^{b}$ & 0.0 \\
\hline$\Delta-6$ desaturation & $46 \cdot 5^{\mathrm{b}}$ & 24.4 & $842 \cdot 9^{a}$ & $166 \cdot 3$ & $65 \cdot 4^{\mathrm{b}}$ & $33 \cdot 1$ & $992 \cdot 5^{\mathrm{a}}$ & $46 \cdot 0$ & $123 \cdot 8^{\mathrm{b}}$ & 29.5 \\
\hline $18: 3 n-3$ to $18: 4 n-3$ & $37 \cdot 1^{\mathrm{b}}$ & $18 \cdot 6$ & $612 \cdot 8^{\mathrm{a}}$ & 114.5 & $0.0^{\mathrm{b}}$ & 0.0 & $681.9^{\mathrm{a}}$ & $26 \cdot 4$ & $18 \cdot 1^{\mathrm{b}}$ & $18 \cdot 1$ \\
\hline $24: 5 n-3$ to $24: 6 n-3$ & $9 \cdot 4$ & $5 \cdot 8$ & $230 \cdot 1$ & 51.9 & 65.4 & $33 \cdot 1$ & 310.5 & $20 \cdot 4$ & $105 \cdot 7$ & 11.4 \\
\hline \multicolumn{11}{|l|}{$n-6$ and $n-3$ PUFA } \\
\hline$\Delta-5$ desaturation & $167 \cdot 4^{\mathrm{b}}$ & 21.5 & $408 \cdot 4^{\mathrm{a}}$ & 84.5 & $44 \cdot 4^{\mathrm{C}}$ & $6 \cdot 9$ & $441.4^{\mathrm{a}}$ & $36 \cdot 2$ & $18 \cdot 9^{\mathrm{C}}$ & $10 \cdot 2$ \\
\hline$\Delta-6$ desaturation & $385.8^{\mathrm{b}}$ & $67 \cdot 1$ & $1068 \cdot 6^{\mathrm{a}}$ & $201 \cdot 3$ & $201.9^{b}$ & $42 \cdot 3$ & $1089 \cdot 1^{a}$ & $67 \cdot 6$ & $174.6^{\mathrm{b}}$ & $62 \cdot 8$ \\
\hline
\end{tabular}

LO, linseed oil-based diet; SO/LO, SO until day 60 and then LO from days 61-96.

${ }_{a, b, c}$ Mean values within a row with unlike superscript letters were significantly different (Tukey's (parametric, $a 5 \%$ ) or Wilcoxon's (non-parametric, $a 1.69 \%$ ) post hoc tests on square root transformed values).

recovery rates in $n$-3 LC-PUFA were also reported for the 10 th day of the period and achieved about $50 \%$ for both the SO/LO and SO/FO fish groups. This means that the recovery in $n-3$ LCPUFA was higher during the first $10 \mathrm{~d}$ of the 36-d experimental period than during the subsequent $26 \mathrm{~d}$ that followed. This observation corresponds to the well-established dilution kinetics following a decreasing exponential curve ${ }^{(8,23,41,50)}$. For example, this phenomenon was previously observed in Atlantic salmon fed a linseed oil diet for 40 weeks and then a fish oil diet for a further 24 weeks, where a DHA recovery rate of $83 \%$ was observed by the end of the 24-week finishing period, while already reaching $79 \%$ by the 16th week of the finishing period $^{(23)}$. Interestingly, the DHA recovery rate was not slower and lower than that of the other $n-3$ LC-PUFA as the recovery rate values were similar on one hand on the short term (day 70) and on the other hand on the long term (day 96).

\section{In vivo fatty acid metabolism}

The whole body fatty acid balance method clearly demonstrated the significantly increased apparent in vivo elongation and desaturation activities with regard to the $n-3$ biosynthesis pathway in fish fed on LO and the $n-6$ pathway in fish fed on SO. The high apparent in vivo bioconversion capacity of rainbow trout fed on plant-based diets is well established ${ }^{(16,19,20)}$ and is confirmed in the present study. In fish fed on LO, $25 \%$ of the consumed ALA was being bioconverted into higher homologues on day 60 of the experiment, while this value reached $27 \%$ on day 96 . In comparison, $27 \%$ of consumed ALA was also bioconverted in fish subjected to the SO/LO treatment from day 61 through day 96. In contrast with the present results, a previous study reported that only $12 \%$ of consumed ALA was bioconverted in rainbow trout with an initial mean weight of approximately $90 \mathrm{~g}$ fed a linseed oil diet for $72 \mathrm{~d}$, with the majority either being accumulated (58\%) or oxidised $(30 \%)^{(20)}$. However, that study used, on one hand, fish with a bigger size than ours, and, on the other hand, diets formulated with $7 \%$ of fishmeal and therefore supplying fish with dietary EPA and DHA ${ }^{(20)}$.

At the end of the experimental period, no differences in apparent in vivo enzyme activity were observed along the $n-3$ pathway between the SO/LO and LO treatments. Moreover, no effects were observed on the 10th day of the experimental period. This indicates that the high $n$-3 PUFA depletion obtained with the SO treatment did not increase the apparent in vivo bioconversion of $n$ - 3 PUFA during the experimental period when ALA-rich linseed oil was present. It thus appears that the fish fatty acid composition has no importance, in contrast to the dietary fatty acid input, on the capacity of fish to convert ALA into $n$-3 LC-PUFA. Interestingly, the present study reported a significant impact of the $n-3$ PUFA depletion on the 
n-6 PUFA bioconversion capacity of SO/LO fish. Indeed, reduced apparent in vivo elongation, as well as apparent in vivo $\Delta-5$ and $\Delta-6$ desaturation activities along the $n-6$ pathway were observed in fish of the $\mathrm{SO} / \mathrm{LO}$ treatment in comparison to those of the LO treatment. These decreased activities related to the $n-6$ pathway should point out that, in the case of fish previously depleted in $n$-3 PUFA, elongases and desaturases neglect the conversion of LA into $n$ - 6 LC-PUFA in the case of an ALA supply. Nevertheless, this did not correspond to increased apparent in vivo elongation or desaturation activities on the $n-3$ pathway and suggests that the effects are not always entirely predictable. In line with the results observed at the end of the 36- $d$ experimental period, at the 10th day sampling point, the activities on the $n-6$ biosynthesis pathway appeared somewhat reduced in the SO/LO fish in comparison to the LO fish group. Recent studies have investigated the impact of $n$ - 3 PUFAdeprived diets on fish fatty acid metabolism and n-3 LC-PUFA deposition/ retention ${ }^{(19,31,32)}$. Francis et al. ${ }^{(19)}$ reported a modulatory effect on $n$-3 LC-PUFA deposition in rainbow trout fed a classic LA-rich sunflower oil diet and then a fish oil diet. The authors reported that the $n-6$ PUFA from the sunflower oil diet evoked a sparing of $n$-3 LC-PUFA from catabolism and resulted in higher $n$-3 LC-PUFA deposition in fish ${ }^{(19)}$. A similar sparing effect was also reported for sunshine bass (Morone chrysops $\times$ Menticirrhus saxatilis) fed a SFA-rich diet for which limited effects of fish oil replacement were reported on fillet fatty acid composition $^{(51,52)}$. More precisely, sunshine bass fed a $50 \%$ coconut oil diet and then a finishing fish oil diet recovered more effectively the $n$-3 LC-PUFA content observed for fish fed a fish oil diet throughout than fish fed three other diets formulated with $50 \%$ grapeseed, linseed, or poultry oils for the grow-out period $^{(52)}$. The authors concluded that dietary SFA appeared to be a preferential substrate for catabolism and induced an increased $n$ - 3 LC-PUFA deposition during the finishing per$\operatorname{iod}^{(52)}$. The present study reported no effect of the fish $n-3$ PUFA depletion on the apparent in vivo enzyme activity along the $n-3$ pathway in the SO/LO fish group, even on the 10th day of the experimental period. Further experiments should be set up to verify the absence of a transient metabolic adaptation in response to a previous shortage in dietary n-3 PUFA, for instance on the 2 nd or 3 rd days of the experimental period. The results of Hagar \& $\mathrm{Hazel}^{(53)}$ support the validity of this suggestion by reporting that in rainbow trout acclimated at either 5 or $20^{\circ} \mathrm{C}$ and then transferred to the opposite temperature, an increase in hepatic $\Delta-6$ desaturase activity within the first $3 \mathrm{~d}$ of temperature transfer before reverting to baseline values on the 6th day was observed. The whole body fatty acid balance method is nevertheless unsuitable for such short experimental periods of a few days and other evaluation tools should thus be used, such as gene expression and enzyme activity measurements at the tissue or cellular level ${ }^{(31,54-58)}$. These approaches should be implemented in further studies specifically focusing on tissues, such as liver and intestine, especially during the 1st day after dietary lipid replacement.

The present study is based on the $n-3$ PUFA depletion of fish with an initial mean weight of $0.7 \mathrm{~g}$, which means fish that were previously fed on a standard diet for about 5 weeks. Complementary studies targeting the previously reported nutritional programming phenomenon ${ }^{(31-33)}$ may be performed. In such studies, the $n-3$ PUFA depletion starts at a much earlier stage, such as at the alevin stage and low $n$ - 3 LC-PUFA diets are used as first feeding and during a short period. For example, a 3-week early exposure of rainbow trout swim-up fry to a diet formulated with rapeseed oil, palm oil and linseed oil improved fish growth, feed intake and FE when the diet was used again 7 months later ${ }^{(33)}$. The lipid bioconversion capacity could also be improved by impacting broodstock. A recent study reported that feeding broodstock gilthead seabream with linseed oil induced longterm effects on the juvenile progeny fed a plant-based diet, as demonstrated by increased fish growth, FE and $\Delta-6$ desaturase gene expression, as compared with juveniles from broodstock fed a fish oil diet ${ }^{(59)}$. In the present study, it was potentially tougher to highlight a difference of apparent in vivo enzyme activity than with other fish species, as rainbow trout possesses a high lipid bioconversion capacity. A similar experiment performed on another species possessing a reduced basal lipid bioconversion capacity might more readily highlight the potential stimulation of a $n-3$ PUFA depletion on the fatty acid bioconversion capacity. As examples, two previous studies on European sea bass reported increased $\Delta-6$ desaturase gene expression in juveniles fed a $n-3$ LC-PUFA deficient diet when previously fed a $n$-3 LC-PUFA deficient larval diet, as compared with groups fed rich $n-3$ LC-PUFA larval diets ${ }^{(31,32)}$. In contrast, the lipid bioconversion capacity of common carp was not improved when fed a traditional cereal diet enriched with $1 \%$ plant-derived oil for $180 \mathrm{~d}$ and then a finishing linseed oil diet or fish oil diet for $30 \mathrm{~d}^{(24)}$.

\section{Conclusions}

The present study demonstrated that the initial high bioconversion capacity of rainbow trout to convert ALA into $n-3$ LC-PUFA was not modulated by a $n$-3 PUFA depletion of fish fatty acid composition through feeding for $60 \mathrm{~d}$ with a diet rich in sunflower oil. Indeed, the apparent in vivo enzyme activities related to that bioconversion remained stable along the $n$ - 3 fatty acid pathway. In contrast, the fish $n$-3 PUFA depletion negatively modulated the $n-6$ PUFA bioconversion capacity of fish in terms of reduced apparent in vivo elongation and desaturation enzyme activities, both on the 10th day and at the end of the 36-d experimental period. Further research on salmonids and other fish species is required to enhance the knowledge on fish fatty acid bioconversion metabolism and to improve fish bioconversion capacity through nutritional intervention strategies.

\section{Acknowledgements}

The authors are very grateful to Marc Michotte and Tarik Abboudi from 'Plateforme technologique en biologie aquicole Marcel Huet' (Université catholique de Louvain) for their help in study design and fish rearing.

The present study was supported by funding from the Belgian National Fund for Scientific Research (FNRS-FRFC 6807370) including a PhD fellowship to J. M. The funders had no role in the design, analysis or writing of the article.

The authors' contributions are as follows: Y. L. and X. R. designed the research; J. B., J. D., Y. L. and X. R. conducted the 
research and sampling; J. M., Y. L. and X. R. analysed the data; F. G., P. K., D. S. F., Y. L. and X. R. assisted J. M. in preparing the manuscript.

The authors declare that there are no conflicts of interest.

\section{References}

1. Gil A \& Gil F (2015) Fish, a Mediterranean source of $n$-3 PUFA: benefits do not justify limiting consumption. BrJ Nutr $\mathbf{1 1 3}$, 58-67.

2. Kris-Etherton PM, Harris WS \& Appel LJ (2002) Fish consumption, fish oil, omega-3 fatty acids, and cardiovascular disease. Circulation 106, 2747-2757.

3. Ruxton CHS, Calder PC, Reed SC, et al. (2005) The impact of long-chain $n$-3 polyunsaturated fatty acids on human health. Nutr Res Rev 18, 113-129.

4. Glencross BD (2009) Exploring the nutritional demand for essential fatty acids by aquaculture species. Rev Aquacult 1, 71-124.

5. National Research Council (2011) Nutrient Requirements of Fish and Shrimp. Washington, DC: National Academies Press.

6. Food and Agriculture Organization (2014) The State of World Fisheries and Aquaculture 2014. Rome: FAO.

7. Tacon AGJ, Hasan MR \& Metian M (2011) Demand and Supply of Feed Ingredients for Farmed Fish and Crustaceans: Trends and Prospects. FAO Fisheries and Aquaculture Technical Paper No. 564 Rome: FAO.

8. Turchini GM, Torstensen BE \& Ng W-K (2009) Fish oil replacement in finfish nutrition. Rev Aquacult 1, 10-57.

9. Tocher DR, Bell JG, MacGlaughlin P, et al. (2001) Hepatocyte fatty acid desaturation and polyunsaturated fatty acid composition of liver in salmonids: effects of dietary vegetable oil. Comp Biochem Physiol B Biochem Mol Biol 130, $257-270$.

10. Castro LFC, Tocher DR \& Monroig O (2016) Long-chain polyunsaturated fatty acid biosynthesis in chordates: insights into the evolution of Fads and Elovl gene repertoire. Prog Lipid Res 62, 25-40.

11. Gregory MK \& James MJ (2014) Rainbow trout (Oncorbynchus mykiss) Elovl5 and Elovl2 differ in selectivity for elongation of omega-3 docosapentaenoic acid. Biochim Biophys Acta 1841, 1656-1660.

12. Seiliez I, Panserat S, Kaushik S, et al. (2001) Cloning, tissue distribution and nutritional regulation of a $\Delta 6$-desaturase-like enzyme in rainbow trout. Comp Biochem Physiol B Biochem Mol Biol 130, 83-93.

13. Hamid NKA, Carmona-Antoñanzas G, Monroig Ó, et al. (2016) Isolation and functional characterisation of a fads 2 in rainbow trout (Oncorbynchus mykiss) with $\Delta 5$ desaturase activity. PLOS ONE 11, e 0150770.

14. Rollin X, Peng J, Pham D, et al. (2003) The effects of dietary lipid and strain difference on polyunsaturated fatty acid composition and conversion in anadromous and landlocked salmon (Salmo salar L.) parr. Comp Biochem Physiol B Biochem Mol Biol 134, 349-366.

15. Thanuthong T, Francis DS, Manickam E, et al. (2011) Fish oil replacement in rainbow trout diets and total dietary PUFA content: II) Effects on fatty acid metabolism and in vivo fatty acid bioconversion. Aquaculture 322-323, 99-108.

16. Turchini GM, Hermon K, Cleveland BJ, et al. (2013) Seven fish oil substitutes over a rainbow trout grow-out cycle: I) Effects on performance and fatty acid metabolism. Aquacult Nutr $\mathbf{1 9}$, 82-94.

17. Stubhaug I, Tocher DR, Bell JG, et al. (2005) Fatty acid metabolism in Atlantic salmon (Salmo salar L.) hepatocytes and influence of dietary vegetable oil. Biochim Biophys Acta 1734, 277-288.

18. Mellery J, Geay F, Tocher DR, et al. (2016) Temperature increase negatively affects the fatty acid bioconversion capacity of rainbow trout (Oncorbynchus mykiss) fed a linseed oil-based diet. PLOS ONE 11, e0164478.

19. Francis DS, Thanuthong T, Senadheera SPSD, et al. (2014) n-3 LC-PUFA deposition efficiency and appetite-regulating hormones are modulated by the dietary lipid source during rainbow trout grow-out and finishing periods. Fish Physiol Biochem 40, 577-593.

20. Turchini GM \& Francis DS (2009) Fatty acid metabolism (desaturation, elongation and $\beta$-oxidation) in rainbow trout fed fish oil- or linseed oil-based diets. Br J Nutr 102, 69-81.

21. Thanuthong T, Francis DS, Senadheera SPSD, et al. (2011) LC-PUFA biosynthesis in rainbow trout is substrate limited: use of the whole body fatty acid balance method and different 18:3n-3/18:2n-6 ratios. Lipids $\mathbf{4 6}, 1111-1127$.

22. Bell JG, Tocher DR, Henderson RJ, et al. (2003) Altered fatty acid compositions in Atlantic salmon (Salmo salar) fed diets containing linseed and rapeseed oils can be partially restored by a subsequent fish oil finishing diet. J Nutr 133, 2793-2801.

23. Bell JG, Henderson RJ, Tocher DR, et al. (2004) Replacement of dietary fish oil with increasing levels of linseed oil: modification of flesh fatty acid compositions in Atlantic salmon (Salmo salar) using a fish oil finishing diet. Lipids 39, 223-232.

24. Schultz S, Koussoroplis AM, Changizi-Magrhoor Z, et al. (2015) Fish oil-based finishing diets strongly increase long-chain polyunsaturated fatty acid concentrations in farm-raised common carp (Cyprinus carpio L.). Aquacult Res 46, 2174-2184.

25. Ng WK, Chong CY, Wang Y, et al. (2013) Effects of dietary fish and vegetable oils on the growth, tissue fatty acid composition, oxidative stability and vitamin E content of red hybrid tilapia and efficacy of using fish oil finishing diets. Aquaculture 372-375, 97-110.

26. Mourente G \& Bell JG (2006) Partial replacement of dietary fish oil with blends of vegetable oils (rapeseed, linseed and palm oils) in diets for European sea bass (Dicentrarchus labrax L.) over a long term growth study: effects on muscle and liver fatty acid composition and effectiveness of a fish oil finishing diet. Comp Biochem Physiol B Biochem Mol Biol 145, 389-399.

27. Glencross BD, Hawkins WE \& Curnow JG (2003) Restoration of the fatty acid composition of red seabream (Pagrus auratus) using a fish oil finishing diet after grow-out on plant oil based diets. Aquacult Nutr 9, 409-418.

28. Turchini GM, Francis DS, Senadheera SPSD, et al. (2011) Fish oil replacement with different vegetable oils in Murray cod: evidence of an 'omega-3 sparing effect' by other dietary fatty acids. Aquaculture 315, 250-259.

29. Thanuthong T, Francis DS, Senadheera SPSD, et al. (2012) Short-term food deprivation before a fish oil finishing strategy improves the deposition of $n$-3 LC-PUFA, but not the washingout of C18 PUFA in rainbow trout. Aquacult Nutr 18, 441-456.

30. Thanuthong T, Francis DS, Senadheera SD, et al. (2011) Fish oil replacement in rainbow trout diets and total dietary PUFA content: I) Effects on feed efficiency, fat deposition and the efficiency of a finishing strategy. Aquaculture 320, 82-90.

31. Vagner M, Robin JH, Zambonino-Infante JI, et al. (2009) Ontogenic effects of early feeding of sea bass (Dicentrarchus labrax) larvae with a range of dietary $n$ - 3 highly unsaturated fatty acid levels on the functioning of polyunsaturated fatty acid desaturation pathways. Br J Nutr 101, 1452-1462.

32. Vagner M, Zambonino Infante JL, Robin JH, et al. (2007) Is it possible to influence European sea bass (Dicentrarchus 
labrax) juvenile metabolism by a nutritional conditioning during larval stage? Aquaculture 267, 165-174.

33. Geurden I, Borchert P, Balasubramanian MN, et al. (2013) The positive impact of the early-feeding of a plant-based diet on its future acceptance and utilisation in rainbow trout. PLOS ONE 8, e83162.

34. Bell MV \& Dick JR (2004) Changes in capacity to synthesise 22:6n-3 during early development in rainbow trout (Oncorbynchus mykiss). Aquaculture 235, 393-409.

35. Rollin X, Mambrini M, Abboudi T, et al. (2003) The optimum dietary indispensable amino acid pattern for growing Atlantic salmon (Salmo salar L.) fry. Br J Nutr 90, 865-876.

36. Choubert G, Delanoue J \& Luquet P (1982) Digestibility in fish: improved device for the automatic collection of feces. Aquaculture 29, 185-189.

37. Association of Official Analytical Chemists (1995) Official Methods of Analysis, 16th ed., vol. 2. Arlington, VA: AOAC International.

38. Furukawa A \& Tsukahara H (1966) On the acid digestion method for the determination of chromic oxide as an index substance in the study of digestibility of fish feed. Nipp SuisGakk 32, 502-506.

39. Folch J, Lees M \& Sloane-Stanley G (1957) A simple method for the isolation and purification of total lipids from animal tissues. J Biol Chem 226, 497-509.

40. Christie WW (1982) Lipid Analysis, 2nd ed. Oxford: Pergamon Press.

41. Turchini GM, Francis DS \& De Silva SS (2006) Modification of tissue fatty acid composition in Murray cod (Maccullochella peelii peelii, Mitchell) resulting from a shift from vegetable oil diets to a fish oil diet. Aquacult Res 37, 570-585.

42. Turchini GM, Francis DS \& De Silva SS (2007) A whole body, in vivo, fatty acid balance method to quantify PUFA metabolism (desaturation, elongation and beta-oxidation). Lipids $\mathbf{4 2}$, 1065-1071.

43. Turchini GM, Francis DS \& De Silva SS (2008) A whole body, in vivo, fatty acid balance method to quantify PUFA metabolism (desaturation, elongation and beta-oxidation). Erratum. Lipids 43, 977.

44. Bransden MP, Carter CG \& Nichols PD (2003) Replacement of fish oil with sunflower oil in feeds for Atlantic salmon (Salmo salar L.): effect on growth performance, tissue fatty acid composition and disease resistance. Comp Biochem Physiol B Biochem Mol Biol 135, 611-625.

45. Menoyo D, López-Bote CJ, Obach A, et al. (2005) Effect of dietary fish oil substitution with linseed oil on the performance, tissue fatty acid profile, metabolism, and oxidative stability of Atlantic salmon. J Anim Sci 83, 2853-2862.

46. Menoyo D, Diez A, Lopez-Bote CJ, et al. (2006) Dietary fat type affects lipid metabolism in Atlantic salmon (Salmo salar L.) and differentially regulates glucose transporter GLUT4 expression in muscle. Aquaculture 261, 294-304.
47. Turchini GM, Francis DS \& De Silva SS (2007) Finishing diets stimulate compensatory growth: results of a study on Murray cod, Maccullochella peelii peelii. Aquacult Nutr 13, 351-360.

48. Torstensen BE, Frøyland L, Ørnsrud R, et al. (2004) Tailoring of a cardioprotective muscle fatty acid composition of Atlantic salmon (Salmo salar) fed vegetable oils. Food Chem 87, 567-580.

49. Francis DS, Peters DJ \& Turchini GM (2009) Apparent in vivo Delta- 6 desaturase activity, efficiency, and affinity are affected by total dietary C18 PUFA in the freshwater fish murray cod. J Agric Food Chem 57, 4381-4390.

50. Robin JH, Regost C, Arzel J, et al. (2003) Fatty acid profile of fish following a change in dietary fatty acid source: model of fatty acid composition with a dilution hypothesis. Aquaculture 225, 283-293.

51. Trushenski JT, Gause B \& Lewis HA (2011) Selective fatty acid metabolism, not the sequence of dietary fish oil intake, prevails in fillet fatty acid profile change in sunshine bass. $N A m J$ Aquacult 73, 204-211.

52. Trushenski JT, Lewis HA \& Kohler CC (2008) Fatty acid profile of sunshine bass: I. Profile change is affected by initial composition and differs among tissues. Lipids $\mathbf{4 3}$, 629-641.

53. Hagar AF \& Hazel JR (1985) Changes in desaturase activity and the fatty acid composition of microsomal membranes from liver tissue of thermally-acclimating rainbow trout. J Comp Physiol B 156, 35-42.

54. Ruyter B, Røjø C, Grisdale-Helland B, et al. (2003) Influence of temperature and high dietary linoleic acid content on esterification, elongation, and desaturation of PUFA in Atlantic salmon hepatocytes. Lipids 38, 833-840.

55. Buzzi M, Henderson RJ \& Sargent JR (1996) The desaturation and elongation of linolenic acid and eicosapentaenoic acid by hepatocytes and liver microsomes from rainbow trout (Oncorbynchus mykiss) fed diets containing fish oil or olive oil. Biochim Biophys Acta 1299, 235-244.

56. Zheng X, Torstensen BE, Tocher DR, et al. (2005) Environmental and dietary influences on highly unsaturated fatty acid biosynthesis and expression of fatty acyl desaturase and elongase genes in liver of Atlantic salmon (Salmo salar). Biochim Biophys Acta 1734, 13-24.

57. Zheng X, Tocher DR, Dickson CA, et al. (2005) Highly unsaturated fatty acid synthesis in vertebrates: new insights with the cloning and characterization of a $\Delta 6$ desaturase of Atlantic salmon. Lipids 40, 13-24.

58. Brown JE (2005) A critical review of methods used to estimate linoleic acid $\Delta 6$-desaturation ex vivo and in vivo. Eur J Lipid Sci Technol 107, 119-134.

59. Izquierdo MS, Turkmen S, Montero D, et al. (2015) Nutritional programming through broodstock diets to improve utilization of very low fishmeal and fish oil diets in gilthead sea bream. Aquaculture 449, 18-26. 